\title{
Prediction of diffusion assisted hydrogen embrittlement failure in high strength martensitic steels
}

Q. Wu and M.A. Zikry*

Department of Mechanical and Aerospace Engineering, North Carolina State

University, Raleigh, North Carolina 27695-7910, USA.

* Corresponding Author. Tel: +1 919-515-5237. Email: zikry@ncsu.edu

\begin{abstract}
A stress assisted hydrogen diffusion transport model, a dislocation-density-based multiple-slip crystalline plasticity formulation, and an overlapping fracture method were used to investigate hydrogen diffusion and embrittlement in lath martensitic steels with distributions of $\mathrm{M}_{23} \mathrm{C}_{6}$ carbide precipitates. The formulation accounts for variant morphologies based on orientation relationships (ORs) that are uniquely inherent to lath martensitic microstructures. The interrelated effects of martensitic block and packet boundaries and carbide precipitates on hydrogen diffusion, hydrogen assisted crack nucleation and growth, are analyzed to characterize the competition between cleavage fracture and hydrogen diffusion assisted fracture along preferential microstructural fracture planes. Stresses along the three cleavage planes and the six hydrogen embrittlement fracture planes are monitored, such that crack nucleation and growth can nucleate along energetically favorable planes. High pressure gradients result in the accumulation of hydrogen, which embrittles martensite, and results in crack nucleation and growth along $\{110\}$ planes. Cleavage fracture occurs along $\{100\}$ planes when there is no significant hydrogen diffusion. The predictions indicate that hydrogen diffusion can
\end{abstract}


suppress the emission and accumulation of dislocation density, and lead to fracture with low plastic strains.

Keywords: Hydrogen embrittlement, Lath martensite, Dislocation-density, Crack nucleation

\section{Introduction}

Hydrogen diffusion in metals and alloys results in embrittlement and fracture due to introduction of hydrogen, which can be due to electrochemistry, diffusion, or external loading conditions (Lynch, 2012; Olden et al., 2008b). Hydrogen embrittlement can be generalized as a three-step sequential process: (1) the introduction of hydrogen into metals, through processes, such as electrochemical charging or gaseous absorption; (2) the transportation of hydrogen atoms through crystalline lattice; (3) the nucleation and growth of hydrogen assisted cracks (Eliaz et al., 2002; Serebrinsky et al., 2004). Several embrittlement mechanisms have been proposed, which include hydride formation and fracture (Lufrano et al., 1996), hydrogen enhanced decohesion (HEDE) (Oriani and Josephic, 1977, 1974), and hydrogen enhanced local plasticity (HELP) (Birnbaum and Sofronis, 1994; Martin et al., 2011).

High strength martensitic steels are extremely susceptible to hydrogen embrittlement, even at very low hydrogen concentrations (Lee et al., 2010; Lee and Gangloff, 2007; Nagao et al., 2012; Ramamurthy and Atrens, 2013). The effects of hydrogen concentration on embrittlement in martensitic steels have been investigated using quasi-static and creep tests, which indicate that hydrogen can decrease tensile strength in a power law manner (Kim et al., 2009; Wang et al., 2007, 2005). 
Microstructural characteristics, such as grain size, carbide precipitates, and retained austenite, can also significantly affect the susceptibility of martensitic steels to hydrogen diffusion and embrittlement due to interfacial effects, such as dislocation-density interactions and interfacial stress mismatches (Craig and Krauss, 1980; Fuchigami et al., 2006; Kim et al., 1986). Hydrogen diffusion assisted microstructural fracture in lath martensitic steel occurs on $\{110\}$ glide planes (Kim and Morris, 1983; Shibata et al., 2012), which is different from the cleavage planes of $\{100\}$ (Guo et al., 2004; Randle and Davies, 2005; Morris, 2011).

Finite element models for hydrogen diffusion have been used to investigate the effects of hydrostatic stress on hydrogen distribution ahead of a stationary crack tip (Krom et al., 1999; Sofronis and McMeeking, 1989; Taha and Sofronis, 2001). Hydrogen assisted crack growth in high strength steels was investigated by the use of a hydrogen dependent cohesive zone model (Serebrinsky et al., 2004) and it was coupled to a stressassisted hydrogen diffusion model, but this approach did not account for the crystalline structure and the inherent anisotropy of martensitic steels. Rimoli and Ortiz (2010) coupled a cohesive zone model and grain boundary diffusion to crystal plasticity to investigate intergranular hydrogen diffusion and embrittlement. However, the critical martensitic characteristics, such as ORs, morphologies, parent austenite orientations, initial dislocation densities, retained austenite, carbide precipitates, and crack growth along specific crystallographic planes were not accounted for in that investigation.

To address these issues, we have adapted a stress-assisted hydrogen diffusion model (Serebrinsky et al., 2004) and a dislocation-density based multiple-slip crystalline plasticity formulation (Wu et al., 2013; Shanthraj and Zikry, 2012; Zikry and Kao, 1996) 
to investigate hydrogen diffusion and embrittlement in lath martensitic steels. In this framework, we account for variant morphologies and ORs that are uniquely inherent to lath martensitic microstructures. A dislocation-density GB interaction scheme that is representative of the resistance to dislocation transmission across martensitic block and packet boundaries has been incorporated into the dislocation-density based crystalline plasticity formulation. A fracture method based on the overlapping element method of Wu and Zikry (2014) and Hansbo and Hansbo (2004), is also used to generate failure surfaces along hydrogen assisted microstructural fracture planes $\{110\}$ as a function of hydrogen concentration and diffusion, carbide precipitate interfaces, dislocation-density evolution, and martensitic block orientations. The formulation is then used to investigate the effects of martensitic block and packet boundaries and carbide precipitates on hydrogen diffusion and embrittlement, and to understand and predict how hydrogen diffusion affects dislocation-density evolution and subsequent martensitic embrittlement.

This paper is organized as follows: the dislocation-density based crystalline plasticity formulation, the derivation of the dislocation-density GB interaction and the stress assisted hydrogen diffusion model are presented in Section 2, the microstructurebased failure criterion, and the numerical implementation of overlapping element method for fracture are outlined in Section 3, the results are presented and discussed in Section 4, and a summary of the results and conclusions are given in Section 5.

\section{Constitutive Formulation}

In this section, only a brief outline of the multiple-slip crystal plasticity ratedependent constitutive formulation and the evolution equations for the mobile and 
immobile dislocation-densities, which are coupled to the constitutive formulation, are presented. A detailed presentation is given by Shanthraj and Zikry (2011).

\subsection{Multiple-slip dislocation-density based crystal plasticity formulation}

The dislocation-density based crystal plasticity constitutive framework used in this study is based on a formulation developed by Zikry (1994), Shanthraj and Zikry (2012), and Ziaei and Zikry (2014), and a brief outline will be presented here. It is assumed that the velocity gradient is decomposed into a symmetric deformation rate tensor $D_{i j}$ and an anti-symmetric spin tensor $W_{i j}$ (Asaro and Rice, 1977). The tensors $D_{i j}$ and $W_{i j}$ are then additively decomposed into elastic and inelastic components as

$$
D_{i j}=D_{i j}^{*}+D_{i j}^{p}, W_{i j}=W_{i j}^{*}+W_{i j}^{p},
$$

The superscript * denotes the elastic part, and the superscript $p$ denotes the plastic part. $W_{i j}^{*}$ includes the rigid body spin. The inelastic parts are defined in terms of the crystallographic slip-rates as

$$
D_{i j}^{p}=\sum_{\alpha} P_{i j}^{(\alpha)} \dot{\gamma}^{(\alpha)}, \text { and } W_{i j}^{p}=\sum_{\alpha} \omega_{i j}^{(\alpha)} \dot{\gamma}^{(\alpha)}
$$

where $\alpha$ is summed over all slip-systems, and $P_{i j}^{(\alpha)}$ and $\omega_{i j}^{(\alpha)}$ are the symmetric and antisymmetric parts of the Schmid tensor in the current configuration respectively.

A power law relation can characterize the rate-dependent constitutive description on each slip system as 


$$
\dot{\gamma}^{(\alpha)}=\dot{\gamma}_{r e f}^{(\alpha)}\left[\begin{array}{l}
\tau^{(\alpha)} \\
\tau_{r e f}^{(\alpha)}
\end{array}\right]\left[\begin{array}{l}
\tau^{(\alpha)} \mid{ }^{1}{ }_{r e f}^{-1} \\
\tau_{r e}^{(\alpha)}
\end{array}\right]^{-}
$$

where $\dot{\gamma}_{\text {ref }}^{(\alpha)}$ is the reference shear strain-rate which corresponds to a reference shear stress $\tau_{r e f}^{(\alpha)}$, and $m$ is the rate sensitivity parameter. $\tau^{(\alpha)}$ is the resolved shear stress on slip system $\alpha$. The reference stress used is a modification of widely used classical forms (Franciosi et al., 1980) that relate reference stress to immobile dislocation-density $\rho_{\text {im }}$ as

$$
\tau_{r e f}^{(\alpha)}=\left(\tau_{y}^{(\alpha)}+G \sum_{\beta=1}^{n s s} b^{(\beta)} \sqrt{a_{\alpha \beta} \rho_{i m}^{(\beta)}}\right)\left(\frac{T}{T_{0}}\right)^{-\xi}
$$

where $\tau_{y}^{(\alpha)}$ is the static yield stress on slip system $\alpha, G$ is the shear modulus, $n s s$ is the number of slip systems, $b^{(\beta)}$ is the magnitude of the Burgers vector, and $a_{\alpha \beta}$ are Taylor coefficients which are related to the strength of interactions between slip-systems (Devincre et al., 2008; Kubin et al., 2008a,b). $T$ is the temperature, $T_{0}$ is the reference temperature, and $\xi$ is the thermal softening exponent, which is chosen as 0.3 .

\subsection{Mobile and immobile dislocation density evolution equations}

Following the approach of Zikry and Kao (1996), it is assumed that, for a given deformed state of the material, the total dislocation-density, $\rho^{(\alpha)}$, can be additively decomposed into a mobile $\rho_{m}^{(\alpha)}$ and an immobile dislocation-density, $\rho_{i m}^{(\alpha)}$. Furthermore, the mobile and immobile dislocation-density rates can be coupled through the formation and destruction of junctions as the stored immobile dislocations act as obstacles for 
evolving mobile dislocations. This is the basis for taking the evolution of mobile and immobile dislocation densities as

$$
\begin{gathered}
\frac{d \rho_{m}^{\alpha}}{d t}=\left|\dot{\gamma}^{\alpha}\right|\left(\frac{g_{\text {sour }}^{\alpha}}{b^{2}}\left(\frac{\rho_{\text {im }}^{\alpha}}{\rho_{m}^{\alpha}}\right)-g_{\text {mnter }-}^{\alpha} \rho_{m}^{\alpha}-\frac{g_{\text {immob- }-}^{\alpha}}{b} \sqrt{\rho_{\text {im }}^{\alpha}}\right), \\
\frac{d \rho_{\text {im }}^{\alpha}}{d t}=\left|\dot{\gamma}^{\alpha}\right|\left(g_{\text {mnter }+}^{\alpha} \rho_{m}^{\alpha}+\frac{g_{\text {immobt }}^{\alpha}}{b} \sqrt{\rho_{\text {im }}^{\alpha}}-g_{\text {recov }}^{\alpha} \rho_{\text {im }}^{\alpha}\right),
\end{gathered}
$$

where $g_{\text {sour }}$ is a coefficient pertaining to an increase in the mobile dislocation-density due to dislocation sources, $g_{m n t e r}$ are coefficients related to the trapping of mobile dislocations due to forest intersections, cross-slip around obstacles, or dislocation interactions, $g_{\text {recov }}$ is a coefficient related to the rearrangement and annihilation of immobile dislocations, and $g_{\text {immob }}$ are coefficients related to the immobilization of mobile dislocations.

\subsection{Determination of dislocation density evolution coefficients}

To couple the evolution equations for mobile and immobile dislocation densities to the crystal plasticity formulation, the non-dimensional coefficients in (Eqs. 5-6) were determined as functions of the crystallography and deformation mode of the material, by considering the generation, interaction and recovery of dislocation densities as discussed in Shanthraj and Zikry (2011). These expressions are summarized in Table 1, where $f_{0}$, and $\varphi$ are geometric parameters. $H_{0}$ is the reference activation enthalpy, $\rho_{s}$ is the saturation density and the average junction length, $l_{c}$, can be approximated as

$$
l_{c}=\frac{1}{\sum_{\beta} \sqrt{\rho_{i m}^{(\beta)}}},
$$


Table 1. $g$ coefficients in equation (5-6)

\begin{tabular}{|c|c|}
\hline g Coefficients & Expression \\
\hline$g_{\text {sour }}^{\alpha}$ & $b^{\alpha} \varphi \sum_{\beta} \sqrt{\rho_{i m}^{\beta}}$ \\
\hline$g_{\text {mnter- }}^{\alpha}$ & \\
\hline$g_{\text {immob- }}^{\alpha}$ & \\
\hline$g_{m n t e r+}^{\alpha}$ & \\
\hline$g_{\text {immob+ }}^{\alpha}$ & \\
\hline$g_{\text {recov }}^{\alpha}$ & $\left.\frac{l_{c} f_{0}}{\dot{\gamma}^{\alpha}} \sum_{k} \sqrt{a_{\alpha \beta}} \frac{\dot{\gamma}^{\beta}}{b^{\beta}}\right) e^{\left(\frac{H_{0}\left(1-\sqrt{\frac{\rho_{i m}^{\alpha}}{\rho_{s}}}\right)}{k T}\right)}$ \\
\hline
\end{tabular}

An interaction tensor, $n_{\alpha}^{\beta \gamma}$, is introduced and defined as having a value of 1 if dislocations on slip-systems $\beta$ and $\gamma$ interact to form an energetically favorable junction on slip system $\alpha$, and a value of 0 if there are no interactions. This interaction tensor is used to map the dislocation-density interactions with the corresponding slip system, and the energy criterion based on Frank's rule is used to determine the formation of junctions. Junction formation, due to the different interaction schemes, is different for b.c.c. (martensite) and f.c.c. $\left(\mathrm{M}_{23} \mathrm{C}_{6}\right.$ carbide precipitates) structures, and details are given in Shanthraj and Zikry (2012). 


\subsection{Dislocation-density GB interaction scheme}

In this section, a dislocation-density GB interaction scheme is presented. The martensitic block boundary can be considered as similar to a grain boundary (GB) interface. For dislocation-density transmission through the boundary, an incoming slip system usually does not completely coincide with an outgoing slip system, and residual dislocations can remain within the boundary due to the conservation of lattice defect vector (Lee et al., 1990; Shi and Zikry, 2009; Sangid et al., 2011; Shanthraj and Zikry, 2013). The energy required to produce the residual dislocation at the boundary is considered as the energy barrier for thermally activated dislocation transmission (Ma et al., 2006; Roters et al., 2010). The constitutive relation Eq. (3) has been modified at the boundary through the introduction of a GB transmission factor (GBTF) based on the energy barrier as

$$
\dot{\gamma}^{(\alpha)}=\dot{\gamma}_{\text {ref }}^{(\alpha)}\left[\frac{\tau^{(\alpha)}}{\tau_{r e f}^{(\alpha)}}\right]\left[\frac{\left[\tau^{(\alpha)} \mid\right.}{\tau_{r e f}^{(\alpha)}}\right]^{\frac{1}{p}-1} G B T F^{(\alpha)},
$$

where $G B T F^{(\alpha)}=e^{\left(\frac{U_{G B}^{(\alpha)}}{k T}\right)}$. It can range from 0 to 1 , where 0 corresponds to full blockage and 1 corresponds to full transmission of dislocation-densities. $U_{G B}^{(\alpha)}$ is the internal energy for slip system $\alpha$ due to the activation of a Frank-Read source in the presence of a GB, $k$ is the Boltzmann constant, and $T$ is the absolute temperature. Based on a line tension model developed by Koning et al. (2002), this energy barrier due to GB residual dislocations, for incoming and outgoing slip systems $\alpha$ and $\beta$, can be postulated as

$$
U_{G B}^{(\alpha \beta)}=\kappa G \Delta b_{e f f}^{2} \Delta_{2},
$$


where $\kappa$ is approximately equal to $0.5, G$ is the shear modulus, $\Delta b_{\text {eff }}$ is the magnitude of the effective residual Burger's vector, which is a function of the misorientation of the slip planes and the magnitude of the true residual Burger's vector. $\Delta_{2}$ is the length of a residual dislocation in the line tension model (Koning et al., 2002), and it is a function of the resolved shear stress for the outgoing slip system $\beta$. Details for calculation of $\Delta b_{\text {eff }}$ and $\Delta_{2}$ are given in Shanthraj and Zikry (2013) and Koning et al. (2002). Dislocationdensity transmission is considered on the most energetically favorable outgoing slip system by taking the lowest value of the energy on all active outgoing slip systems, as

$$
U_{G B}^{(\alpha)}=\min _{\beta} U_{G B}^{(\alpha \beta)}
$$

\subsection{Stress-assisted hydrogen diffusion}

Hydrogen atoms in the metal lattice are assumed to initiate as points defects, which can cause dilatational distortion, and interact with the stress field through the pressure $p=\operatorname{Tr}(\sigma) / 3$ (Serebrinsky et al., 2004). The pressure is assumed as positive for tensile stresses. The stress-assisted hydrogen diffusion equation, based on a modification of Fick's second law of diffusion (Dadfarnia et al., 2014; Olden et al., 2008b; Serebrinsky et al., 2004), which is related to the spatial gradients of hydrogen concentration and pressure, and it is given by

$$
\frac{\partial C}{\partial t}=D \nabla^{2} C-\nabla \cdot\left(\frac{D V_{H}}{R T} C \nabla p\right),
$$

where $C$ is the hydrogen concentration, $D$ is the hydrogen diffusion coefficient, $V_{\mathrm{H}}$ is the partial molar volume of hydrogen in steels, and equal to $2.0 \times 10^{-6} \mathrm{~m}^{3} / \mathrm{mol}$ (Sofronis and 
McMeeking, 1989), $R$ is the universal gas constant, $T$ is the absolute temperature. A finite element approach, based on the pressure gradient formulation given by Krom et al. (1999), is used to solve Eq. 11.

\section{Microstructural failure criterion and computational implementation of overlapping element method}

\subsection{Microstructurally-based failure criterion}

The inherent hydrogen diffusion assisted fracture mode in martensitic steel occurs on $\{110\}_{\alpha}$, planes (Kim and Morris, 1983; Shibata et al., 2012). To account for this as a microstructural failure criterion, the orientation of the fracture planes for each variant in the global coordinate system is obtained by applying the series of transformations outlined in Wu and Zikry (2014) as

$$
n_{\text {fracture }}=[T]_{3}[T]_{2}[T]_{1} n_{\text {fracture }, \alpha^{\prime}} .
$$

In this equation, the first transformation, $[\mathrm{T}]_{1}$, relates an observed $\mathrm{OR}$ to a theoretical OR, such as Kurdjumov-Sachs (KS) and Nishiyama-Wassermann (NW) ORs. The second transformation, $[\mathrm{T}]_{2}$, relates a martensite OR to the parent austenite Euler grain orientation. The third transformation, $[\mathrm{T}]_{3}$, relates the parent austenite Euler grain orientation to the global coordinates.

The global orientation of the fracture planes in the current configuration is then

obtained by updating, at every time-step, due to the lattice rotations as $\dot{n}_{\text {fracture }}=W^{*} n_{\text {fracture }}$. The normal component of the traction acting on each fracture plane has a direct influence on fracture along that plane (Musienko and Cailletaud, 2009; Pouillier et al., 2012). The 
maximum, over all the $\{110\}_{\alpha^{\prime}}$ fracture planes, of the normal component of the traction on these planes is, therefore, monitored and compared with a critical fracture stress $\sigma_{\mathrm{c}}$ to determine failure. The failure criterion for hydrogen embrittlement is then given by

$$
t_{\text {fracture }}>\sigma_{c} \text {, }
$$

where $t_{\text {fracure }}=\max _{\{110\} \text { planes }}\left\langle n_{\text {fracture }}^{T}[\sigma] n_{\text {fracture }}\right\rangle$.

The presence of hydrogen decreases the critical fracture stress, and an empirical power law based on different experiments (Wang et al., 2007, 2005; Kim et al., 2009), between the critical fracture stress and hydrogen concentration, is, therefore, applied on the $\{110\}$ fracture planes as,

$$
\sigma_{c}=\sigma_{c 0} C^{-0.14}
$$

where $\sigma_{\mathrm{c} 0}$ is the initial critical fracture stress on $\{110\}$ planes at a hydrogen concentration of $1 \mathrm{ppm}, C$ is the hydrogen concentration. The reduction of the critical fracture stress (RCFS), which represents embrittlement of martensite, is defined as

$$
R C F S=\frac{\sigma_{c 0}-\sigma_{c}}{\sigma_{c 0}} .
$$

The failure criterion for cleavage-assisted fracture is based on the normal component of traction on $\{100\}_{\alpha}$, cleavage planes, and the critical fracture stress is constant (Shanthraj and Zikry, 2013; Wu and Zikry, 2014). For the hydrogen embrittlement cases, stresses on hydrogen-assisted fracture planes $\{110\}$ and cleavage planes $\{100\}$ are both monitored to track the material competition between hydrogen 
diffusion assisted fracture and cleavage fracture. For the cases without hydrogen embrittlement, only stresses on cleavage planes $\{100\}$ are monitored for failure.

\subsection{Computational implementation of overlapping element method}

We follow the approach of Wu and Zikry (2014) and Hansbo and Hansbo (2004), and consider one element crossed by a crack defined implicitly $f(X)=0$, dividing the element domain into two subdomains with areas $A_{e l}$ and $A_{e 2}$ (Fig. 1). The direction of crack propagation would be along the most favorable fracture plane (Morris, 2011; Shibata et al., 2012; Wang et al., 2008). Adding phantom nodes on top of the existing nodes, the original cracked element is replaced by two overlapping elements. The two overlapping elements do not share nodes, and therefore can have independent displacement fields. For each overlapping element, only the subdomain with area $A_{e l}$ or

$A_{e 2}$ (Fig. 1), corresponding to one of the two subdomains for the original cracked element, is considered as active. When the failure criterion is attained in one element, the elastic energy stored in the element will be released. Numerical instability can be encountered, because the resolved shear stresses, slip rates, and dislocation densities can vary widely, due to decreases in stiffness caused by introducing crack surfaces. To address these numerical issues, the stresses are unloaded as a function of elastic energy and plastic work. After the stresses have been unloaded, overlapping elements are introduced to represent failure surface. Details for implementation of overlapping element method are given in Wu and Zikry (2014).

\subsection{Computational techniques for dislocation-density-based crystal plasticity}


The total deformation rate tensor, $D_{i j}$, and the plastic deformation rate tensor, $D_{i j}^{p}$, are needed to update the material stress state. The method used here is the one developed by Zikry (1994) and Shanthraj and Zikry (2011) for rate-dependent crystalline plasticity formulations, and only a brief outline will be presented here. For quasi-static deformations, an implicit FE method with BFGS iteration is used to obtain the total deformation rate tensor, $D_{i j}$. To overcome numerical instabilities associated with stiffness, a hybrid explicit-implicit method is used to obtain the plastic deformation rate tensor, $D_{i j}^{p}$. This hybrid numerical scheme is also used to update the evolutionary equations for the mobile and immobile dislocation densities.

\section{Results and discussion}

The multiple-slip dislocation-density-based crystal plasticity and the fracture formulations were coupled within the nonlinear FEM framework to investigate hydrogen assisted crack nucleation and growth in martensitic steels with distributions of $\mathrm{M}_{23} \mathrm{C}_{6}$ carbide precipitates. We used a combination of blocks and packets to represent the martensite's microstructure. This approach is based on the approach developed by Hatem and Zikry (2009). Blocks are collections of laths with low misorientation, and packets are collections of blocks that have the same habit plane (Morito et al., 2006, 2003). In this study, 40 martensitic blocks were distributed randomly within 14 packets from one parent austenite grain. The variant arrangements, representing the orientation relationships between the parent austenite grain and martensitic blocks, were based on experimental EBSD observations (Kitahara et al., 2006; Morito et al., 2003). It was also assumed that the $\mathrm{M}_{23} \mathrm{C}_{6}$ carbide precipitates had a representative volume fraction of $2 \%$ (see, for 
example, Abe, 2008), and that they were mainly distributed along block/packet boundaries (Kipelova et al., 2013; Taneike et al., 2004). The $\mathrm{M}_{23} \mathrm{C}_{6}$ carbide precipitates are f.c.c. (Padilha and Rios, 2002; Shen et al., 2012; Terada et al., 2006) and assumed to be coincident with the parent austenite orientations (Shtansky et al., 2000; Song et al., 2010), and the interfaces between $\mathrm{M}_{23} \mathrm{C}_{6}$ carbide precipitates and martensite are generally fully coherent or semi-coherent depending on the size of carbide precipitates (Gustafson and Hättestrand, 2002; Hald and Korcakova, 2003; Kipelova et al., 2013). In this investigation, we assumed these interfaces as coherent. The material properties (Table 2) that are used are representative of low-carbon martensitic steel (Bowen and Knott, 1986; Di Schino and Guarnaschelli, 2009; Krauss, 1999) and carbide precipitates $\mathrm{M}_{23} \mathrm{C}_{6}$ (Han et al., 2012; Jiang, 2008; Olden et al., 2008a).

Table 2 Material Properties

\begin{tabular}{|l|l|l|}
\hline \multicolumn{1}{|c|}{ Properties } & \multicolumn{1}{c|}{$\begin{array}{c}\text { Carbide } \\
\text { Precipitates, } \\
\mathbf{M}_{23} \mathbf{C}_{6}\end{array}$} & \multicolumn{1}{|c|}{ Martensite } \\
\hline Young's modulus, $E$ & $357 \mathrm{GPa}$ & $228 \mathrm{GPa}$ \\
\hline Static yield stress, $\tau_{\mathrm{y}}$ & $1.65 \mathrm{GPa}$ & $517 \mathrm{MPa}$ \\
\hline Poisson's ratio, $v$ & 0.3 & 0.3 \\
\hline Rate sensitivity parameters, $\mathrm{m}$ & 0.01 & 0.01 \\
\hline Reference strain rate, & $0.001 \mathrm{~s}^{-1}$ & $0.001 \mathrm{~s}^{-1}$ \\
\hline Critical strain rate, & $10^{4} \mathrm{~s}^{-1}$ & $10^{4} \mathrm{~s}^{-1}$ \\
\hline Burger vector, b & $\mathrm{N} / \mathrm{A}$ & $3.0 \times 10^{-10} \mathrm{~m}$ \\
\hline $\begin{array}{l}\text { Initial immobile dislocation } \\
\text { density } \rho_{\text {im }}^{0}\end{array}$ & $\mathrm{~N} / \mathrm{A}$ & $1.0 \times 10^{10} \mathrm{~m}^{-2}$ \\
\hline $\begin{array}{l}\text { Initial mobile dislocation density } \\
\rho_{m}^{0}\end{array}$ & $\mathrm{~N} / \mathrm{A}$ & $1.0 \times 10^{7} \mathrm{~m}^{-2}$ \\
\hline Saturation dislocation density, $\rho_{s}$ & $\mathrm{~N} / \mathrm{A}$ & $1.0 \times 10^{16} \mathrm{~m}^{-2}$ \\
\hline $\begin{array}{l}\text { Fracture stress on }\{100\} \text { planes, } \\
\sigma_{\text {frac }}\end{array}$ & $2 \tau_{\mathrm{y} \_ \text {precipitate }}$ & $5 \tau_{\mathrm{y} \_ \text {martensite }}$ \\
\hline
\end{tabular}




\begin{tabular}{|l|l|l|}
\hline $\begin{array}{l}\text { Initial fracture stress on }\{110\} \\
\text { planes, } \sigma_{c} 0\end{array}$ & $2 \tau_{\mathrm{y} \_ \text {precipitate }}$ & $4 \tau_{\mathrm{y}_{-} \text {martensite }}$ \\
\hline Hydrogen diffusion coefficient, $D$ & $2.0 \times 10^{-16} \mathrm{~m}^{2} / \mathrm{s}$ & $8.2 \times 10^{-10} \mathrm{~m}^{2} / \mathrm{s}$ \\
\hline
\end{tabular}

The parent austenite grain was oriented based on the loading plane of $\left(\begin{array}{lll}0 & 0 & 1\end{array}\right)_{\gamma}$ and the loading direction of $\left[\begin{array}{lll}0 & 1 & 0\end{array}\right]_{\gamma}$. The parent austenite grain was assumed as having a cube Euler orientation of $\left(0^{\circ}, 0^{\circ}, 0^{\circ}\right)$. The Kurdjumov-Sachs (KS) OR was adopted as the martensite OR, and $\{111\}_{\gamma}$ was assumed as the habit plane. An initial hydrogen concentration of $1 \mathrm{ppm}$ was chosen, and a constant hydrogen concentration of $10 \mathrm{ppm}$ was applied on the left surface of the model. A convergent plane strain FE mesh of 4931 bilinear quadrilateral elements was used with a specimen size of $3.2 \mathrm{~mm} \times 6.4 \mathrm{~mm}$, and a displacement load was applied on the top surface for a nominal strain rate of $1.0 \times 10^{-5} \mathrm{~s}^{-1}$

(Fig. 2). Furthermore, since the strain-rates are quasi-static, adiabatic heating and thermal softening effects would be negligible.

\subsection{Hydrogen diffusion}

In this section, we will discuss how hydrogen diffusion is affected by microstructural effects, such as carbide precipitates and martensitic block boundaries. The hydrogen concentration at a nominal strain of $2 \%$, corresponding to a time of $2000 \mathrm{~s}$, is shown in Fig. 3(a). Hydrogen diffused and accumulated around the precipitates, as indicated by the hydrogen concentration of $9 \mathrm{ppm}$, which is slightly less than the specified boundary condition of $10 \mathrm{ppm}$. With increases in time and loading, hydrogen continued to diffuse and accumulate at the precipitate interfaces. The maximum hydrogen concentration at a nominal strain of $6 \%$ was approximately $18 \mathrm{ppm}$, and it occurred around the carbide precipitate, which is denoted by the red circle (Fig. 3(b)). The high 
concentration of hydrogen around the precipitate is related to pressure (cf. Eq. 11). This can be seen in Fig. 3(c), where the normalized (by the static yield stress of martensite) tensile pressure around the precipitate was 4.5 , and this pressure accumulation resulted in large pressure gradients. The normalized norm $\left(L^{2}\right.$ norm $)$ of the pressure gradient around the precipitates was approximately $2.4 \times 10^{4}$ (Fig. 3(d)), and this large pressure gradient can generate a stress driven flux of hydrogen toward the precipitate (Miresmaeili et al., 2010), which can result in hydrogen accumulation.

The large pressure gradient can be due to microstructural defects, such as dislocation-densities (see, for example, Shanthraj and Zikry, 2012). The normalized (by the initial immobile dislocation density of martensite) immobile dislocation density and GBTF, corresponding to the active slip system in martensite $(1 \overline{1} 2)[\overline{1} 11]$ at a nominal strain of $6 \%$, are shown in Figs. 4(a-b). The maximum normalized immobile dislocation density was $2.0 \times 10^{4}$, which occurred around the peripheries of the carbide precipitates. Slip system incompatibilities, as represented by the low GBTF at the interface of precipitate and martensite, and martensitic blocks boundaries (Fig. 4(b)), impeded dislocation density transmission and resulted in high local stresses (Fig. 4(c)). The maximum normalized (by the static yield stress of martensite) normal stress was 8 , and occurred around the precipitates. These high local stresses around the precipitates further activated slip systems, and promoted martensitic inelastic deformation as indicated by the accumulation of shear slip, which attained a maximum of 0.14 (Fig. 4(d)). The low shear slips in carbide precipitates (Fig. 4(d)) indicate that these hard precipitates deformed elastically.

\subsection{Hydrogen diffusion assisted fracture}


In this section, hydrogen diffusion assisted fracture has been investigated, and compared with the case without hydrogen embrittlement. As discussed in Section 4.1, carbide precipitate can impede dislocation transmission and result in high local stresses around the precipitate. These high local stresses can not only lead to hydrogen accumulation, which decreases critical fracture stress, but also resolve large stress components perpendicular to the favorable fracture planes, which act as a driving mechanism for crack nucleation and growth along the favorable planes. It was assumed that cleavage fracture can occur along the three $\{100\}$ planes, and that hydrogen diffusion assisted fracture can occur along the six $\{110\}$ planes (Shibata et al., 2012). Therefore, the stresses on all these nine planes were monitored to determine whether cleavage assisted fracture or diffusion assisted fracture would occur. The maximum normalized cleavage stress on the three cleavage planes $\{100\}$ at a nominal strain of $1 \%$ is shown in Fig. 5(a). The maximum normalized cleavage stress of 3.2 occurred within the carbide precipitates, while the cleavage stress in martensite had a lower value of 2.2 . The maximum normalized fracture stress, on the six hydrogen embrittlement fracture planes $\{110\}$ at a nominal strain of $1 \%$ is shown in Fig. 5(b). The maximum normalized value was approximately 3.4 , and it occurred at the interface of martensite and the carbide precipitates. The embrittlement due to the accumulation of hydrogen around the carbide precipitates and the large stresses on the $\{110\}$ fracture planes resulted in a crack nucleating at a nominal strain of $1.8 \%$ (Fig. 5(c)). Crack nucleation, at such a low nominal strain, is an indication of embrittlement. After crack nucleation, the crack propagated with a small crack opening displacement (Fig. 5(d)). The maximum normal stress at a nominal strain of $2.2 \%$ was 4.5 , and it occurred ahead of crack front. 
The high local normal stress resulted in large pressure and pressure gradients ahead of the crack front. The maximum normalized tensile pressure was 2 (Fig. 6(a)), and the maximum normalized norm of pressure gradient was $1.4 \times 10^{4}$ (Fig. $6(\mathrm{~b})$ ). These high pressure gradients ahead of the crack front generated a stress driven flux of hydrogen toward the crack front, which resulted in the accumulation of hydrogen ahead of crack front at a concentration of $11 \mathrm{ppm}$ (Fig. 6(c)). The high concentration of hydrogen embrittled martensitic blocks, and it resulted in a large reduction of the critical fracture stress on hydrogen embrittlement fracture planes $\{110\}$ as indicated by the value of 0.28 ahead of the crack front (Fig. 6(d)). In combination with high crack opening-mode stresses, this accelerated crack growth.

The nominal stress-strain curves for the hydrogen embrittlement case and for the case without embrittlement are shown in Fig. 7. In comparison with the case without embrittlement, the crack nucleated at a much lower nominal strain and propagated at a faster rate. The differences in crack nucleation and propagation between the hydrogen embrittlement case and the case without embrittlement are related to how hydrogen diffuses at the interfaces of the martensitic blocks and the carbide precipitates, which results in embrittlement.

The normalized total dislocation density generations for the hydrogen embrittlement case and for the case without embrittlement are shown in Figs. 8(a-b). The maximum total dislocation density generation for the hydrogen embrittlement case, at a nominal strain of $2.8 \%$, was $8.0 \times 10^{4}$ (Fig. $8(a)$ ), and it occurred ahead of crack front. The maximum total dislocation density generation for the case without embrittlement, at a nominal strain of $10 \%$, was $4.5 \times 10^{5}$ (Fig. $8($ b)), which was approximately 5.5 times of 
that for the hydrogen embrittlement case. This indicates that accumulation of hydrogen ahead of the crack front suppressed dislocation density generation, which is consistent with the predictions from molecular dynamics simulations (Song and Curtin, 2013). This high dislocation density generation resulted in large plastic deformation. The maximum shear slip for the hydrogen embrittlement case was 0.22 (Fig. 8(c)), while the maximum shear slip for the case without embrittlement was 0.55 (Fig. 8(d)), which was 2.5 times of that for the hydrogen embrittlement case. Furthermore, the fracture paths for these two cases were different, since lath martensite fractured on $\{110\}$ planes for the hydrogen embrittlement cases (Kim and Morris, 1983; Nagao et al., 2012; Shibata et al., 2012), and on $\{100\}$ cleavage planes without hydrogen embrittlement (Guo et al., 2004; Morris, 2011).

\subsection{Dislocation gradient effects}

As the shear slip results (Figs. 8(c-d)) indicated, there are large changes over small length scales, which is an indication that gradients of plastic strain can lead to the formation of geometrically necessary dislocations (GNDs), which can relax strain gradients (Kubin and Mortensen, 2003; Rezvanian et al., 2007). For crystalline materials, the formula for calculating GND densities (Rezvanian et al., 2007; Elkhodary and Zikry, 2011) can be obtained as

$$
\begin{aligned}
& \rho_{\text {screw }}^{(\alpha)}=-\frac{1}{b^{(\alpha)}} \ell^{(\alpha)} \cdot \nabla \gamma^{(\alpha)}, \\
& \rho_{\text {edge }}^{(\alpha)}=-\frac{1}{b^{(\alpha)}} s^{(\alpha)} \cdot \nabla \gamma^{(\alpha)},
\end{aligned}
$$


where $\rho_{\text {screw }}^{(\alpha)}$ are GND screw dislocation densities and $\rho_{\text {edge }}^{(\alpha)}$ are GND edge dislocation densities for slip system $\alpha, \ell^{\alpha)}$ is the dislocation line vector, $s^{(\alpha)}$ is the slip direction, and $\gamma^{(\alpha)}$ is the plastic shear strain.

The normalized (by the initial immobile dislocation density of martensite) GND screw dislocation densities for the most active slip system $(\overline{1} 10)[11 \overline{1}]$ for the hydrogen embrittlement case, for the local region denoted by the red circle in Fig. 8(c), are shown in Figs. 9(a-b). The GND screw dislocation densities evolve as loops, and the GND dislocation density lines and loops are equivalent to the actual dislocation lines and loops (Elkhodary and Zikry, 2011; Rezvanian et al., 2007). Fig. 9(a) shows one dislocation density loop with a maximum value of 35 nucleated from a carbide precipitate at a nominal strain of $1.7 \%$, and then several small dislocation density loops with the same values were generated by the propagating crack (Fig. 9(b)). The normalized GND screw dislocation densities for the most active slip system (110)[1 111$]$, for the case without embrittlement at a nominal strain of $6 \%$, for the local region denoted by the red circle in Fig. 8(d), are shown in Fig. 9(c). Dislocation density loops nucleated from the crack front. As the nominal strain increases, the loops expanded, and new dislocation density loops occurred at the crack front (Fig. 9(d)). Furthermore, the maximum normalized value of GND screw dislocation densities increased from 35 at 6\% nominal strain (Fig. 9(c)) to 180 at $8.4 \%$ nominal strain (Fig. 9(d)). These dislocation loops ahead of crack front can relax tensile stresses, blunt the cracks, and improve fracture toughness (Higashida et al., 2008, 2000), which retarded crack growth (Fig. 10). The hydrogen embrittlement case had fewer dislocation density loops and lower dislocation density values, which further 
indicates that the diffusion of hydrogen suppressed the emission of dislocation loops and embrittled martensite, and resulted in cracks propagation at low nominal strains (Fig. 10). In comparison with the behavior of statistically stored dislocations (SSDs) densities (Figs. 8(a-b)), GND screw dislocation densities evolved as loops, while SSD dislocation densities evolved as accumulations. The GND screw dislocation densities were 3 orders of magnitude less than SSD dislocation densities, but the presence of the GNDs provides a measure of local strengthening mechanisms and dislocation-density loops ahead of the crack front.

\subsection{Hydrogen diffusion and embrittlement with a pre-existing crack}

In this section, the effects of a model with a pre-existing crack on hydrogen embrittlement have been investigated, and a pre-existing crack with the normalized initial crack length of $a / w$ of 0.1 was used, where $a$ is the crack length and $w$ is the specimen width. The pressure and norm of pressure gradient at a nominal strain of $0.3 \%$ are shown in Figs. 11(a-b). The stress accumulation caused by the pre-existing crack resulted in large tensile pressures ahead of the crack front with a maximum normalized value of 1.6 (Fig. 11(a)), which subsequently led to large pressure gradients. The maximum norm of pressure gradient was approximately 8000, and it occurred ahead of crack front (Fig. 11(b)), which would generate a stress assisted hydrogen flux toward the crack front, and it resulted in the accumulation of hydrogen with maximum concentrations of 9 ppm (Fig. 11(c)). This high concentration of hydrogen embrittled the martensitic blocks, as indicated by the large reduction of the critical fracture stress at a value of 0.26 (Fig. 11(d)), which resulted in crack propagation and growth at low nominal strains (Fig. 13). 
The normal stress at a nominal strain of $2 \%$ for hydrogen embrittlement case is shown in Fig. 12(a). At such a low nominal strain, the crack had already cut through the model with a small crack opening displacement. Fig. 12(b) shows the normal stress at the same nominal strain for the case without hydrogen embrittlement. The crack had propagated a short distance, cut through one carbide precipitate, then was blunted or impeded by the high strength martensitic block, as indicated by the large normalized normal stress of 5.5 ahead of the crack front (Fig. 12(b)) and the crack extension curve (Fig. 13). Crack paths for these two cases were significantly different due to the different fracture planes of cleavage and hydrogen embrittlement.

As noted earlier, hydrogen embrittlment is related to dislocation-density evolution and plastic deformation. The normalized immobile dislocation densities for the most active slip system ( $\overline{1} 12)[1 \overline{1} 1]$, at a nominal strain of $2 \%$ for the hydrogen embrittlement case, are shown in Fig. 14(a). The maximum dislocation density was approximately 5000, and it occurred when the crack changed orientation due to the misorientation of martensitic blocks. The maximum normalized immobile dislocation density for the most active slip system $(11 \overline{2})[111]$, at a nominal strain of $4 \%$ for the case without embrittlement, was $6.0 \times 10^{4}$ (Fig. 14(b)), which occurred ahead of crack front, and was 12 times of that for the hydrogen embrittlement case. The maximum shear slip for hydrogen embrittlement case was 0.05 (Fig. 14(c)), while for the case without embrittlement it was 0.4 (Fig. 14(d)), which was 8 times of that for the hydrogen embrittlement case. These results further substantiate that hydrogen can suppress dislocation activity, embrittle martensite, and result in crack propagation at low nominal strains due to lower plastic deformation and dislocation-density evolution and 
accumulation. In comparison with the hydrogen embritttlement case, without a preexisting crack (Fig. 5), this case resulted in higher local tensile pressures and hydrogen accumulations (Fig. 11), which accelerated embrittlement and crack growth (Fig. 13), and resulted in failure at a lower strain (Fig. 12(a)).

\section{Conclusions}

A stress-assisted hydrogen diffusion model has been coupled to a dislocationdensity-based, multi-slip crystal plasticity formulation to investigate the effects of microstructure on hydrogen diffusion and embrittlement in martensitic steels with and without pre-existing cracks. A microstrucutrally-based failure criterion and overlapping element method were then used to investigate hydrogen-assisted crack nucleation and propagation in martensitic steels with distributions of $\mathrm{M}_{23} \mathrm{C}_{6}$ carbide precipitates.

The predictions indicate that low transmission martensitic block boundaries and carbide precipitates impeded dislocation density transmission, resulted in large tensile pressure and pressure gradients, and led to the accumulation of hydrogen, which locally embrittled martensitic steels. Large opening-mode stresses resulted in crack nucleation at low nominal strains along $\{110\}$ planes. Stresses on all the three cleavage planes and the six hydrogen embrittlement planes were monitored for critical values, such that crack nucleation and growth would occur along the most preferential planes. The high tensile stresses ahead of the crack fronts resulted in large pressures and pressure gradients, which led to hydrogen accumulation, a significant reduction of the critical fracture stress, and an acceleration of crack propagation. Dislocation-densities, due to geometrically necessary screw dislocation loops ahead of the crack front relaxed tensile stresses, blunted the 
cracks, and retarded crack propagation. In the absence of hydrogen diffusion and embrittlement, cracks nucleated and propagated along the $\{100\}$ planes and had significantly different orientations and paths in comparison with the hydrogen embrittlement case. The pre-existing crack in hydrogen embrittlement case resulted in higher local tensile pressures and hydrogen accumulations, which accelerated embrittlement and crack growth, and resulted in failure at a lower strain in comparison with the hydrogen embritttlement case without pre-existing crack.

\section{Acknowledgment}

Support from the Office of Naval Research through Grant N000140510097 is gratefully acknowledged.

\section{References}

Abe, F., 2008. Precipitate design for creep strengthening of $9 \% \mathrm{Cr}$ tempered martensitic steel for ultra-supercritical power plants. Sci. Technol. Adv. Mater. 9, 1-15.

Asaro, R.J., Rice, J.R., 1977. Strain localization in ductile single crystals. J. Mech. Phys. Solids 25, 309-338.

Birnbaum, H.K., Sofronis, P., 1994. Hydrogen-enhanced localized plasticity-a mechanism for hydrogen-related fracture. Mater. Sci. Eng. A 176, 191-202.

Bowen, P., Knott, J.F., 1986. Size effects on the microscopic cleavage fracture stress, $\sigma_{F}^{*}$, in martensitic microstructures. Metall. Trans. A 17, 231-241.

Craig, B.D., Krauss, G., 1980. The structure of tempered martensite and its susceptibility to hydrogen stress cracking. Metall. Trans. A 11, 1799-1808.

Dadfarnia, M., Somerday, B.P., Schembri, P.E., Sofronis, P., Foulk, J.W., Nibur, K. a., Balch, D.K., 2014. On Modeling Hydrogen-Induced Crack Propagation Under Sustained Load. Jom 66.

Di Schino, A., Guarnaschelli, C., 2009. Effect of microstructure on cleavage resistance of high-strength quenched and tempered steels. Mater. Lett. 63, 1968-1972. 
Devincre, B., Hoc, T., Kubin, L., 2008. Dislocation mean free paths and strain hardening of crystals. Science 320, 1745-8.

Eliaz, N., Shachar, A., Tal, B., Eliezer, D., 2002. Characteristics of hydrogen embrittlement, stress corrosion cracking and tempered martensite embrittlement in high-strength steels. Eng. Fail. Anal. 9, 167-184.

Elkhodary, K.I., Zikry, M.A., 2011. A fracture criterion for finitely deforming crystalline solids-The dynamic fracture of single crystals. J. Mech. Phys. Solids 59, 20072022.

Franciosi, P., Berveiller, M., Zaoui, A., 1980. Latent hardening in copper and aluminium single crystals. Acta Metall. 28, 273-283.

Fuchigami, H., Minami, H., Nagumo, M., 2006. Effect of grain size on the susceptibility of martensitic steel to hydrogen-related failure. Philos. Mag. Lett. 86, 21-29.

Guo, Z., Lee, C.S., Morris, J.W., 2004. On coherent transformations in steel. Acta Mater. 52, 5511-5518.

Gustafson, Å., Hättestrand, M., 2002. Coarsening of precipitates in an advanced creep resistant $9 \%$ chromium steel-quantitative microscopy and simulations. Mater. Sci. Eng. A 333, 279-286.

Hald, J., Korcakova, L., 2003. Precipitate Stability in Creep Resistant Ferritic SteelsExperimental Investigations and Modelling. ISIJ Int. 43, 420-427.

Han, J.J., Wang, C.P., Liu, X.J., Wang, Y., Liu, Z.-K., 2012. First-principles calculation of structural, mechanical, magnetic and thermodynamic properties for _-M23C6 (M $=\mathrm{Fe}, \mathrm{Cr}$ ) compounds. J. Phys. Condens. Matter 24, 505503.

Hansbo, A., Hansbo, P., 2004. A finite element method for the simulation of strong and weak discontinuities in solid mechanics. Comput. Methods Appl. Mech. Eng. 193, 3523-3540.

Hatem, T.M., Zikry, M.A., 2009. Shear pipe effects and dynamic shear-strain localization in martensitic steels. Acta Mater. 57, 4558-4567.

Higashida, K., Narita, N., Asano, S., Onodera, R., 2000. Dislocation emission from a crack tip in $\mathrm{MgO}$ thin crystals. Mater. Sci. Eng. A 285, 111-121.

Higashida, K., Tanaka, M., Hartmaier, a., Hoshino, Y., 2008. Analyzing crack-tip dislocations and their shielding effect on fracture toughness. Mater. Sci. Eng. A 483$484,13-18$. 
Jiang, C., 2008. First-principles study of structural, elastic, and electronic properties of chromium carbides. Appl. Phys. Lett. 92, 041909.

Kim, J.S., Lee, Y.H., Lee, D.L., Park, K.-T., Lee, C.S., 2009. Microstructural influences on hydrogen delayed fracture of high strength steels. Mater. Sci. Eng. A 505, 105110 .

Kim, Y.H., Kim, H.J., Morris, J.W., 1986. The Influence of Precipitated Austenite on Hydrogen Embrittlement in 5 . 5Ni Steel. Metall. Trans. A 17, 1157-1164.

Kim, Y.H., Morris, J.W., 1983. The Nature of Quasicleavage Fracture in Tempered 5. 5Ni Steel after Hydrogen Charging. Metall. Trans. A 14, 1883-1888.

Kipelova, a., Belyakov, a., Kaibyshev, R., 2013. The crystallography of M 23 C 6 carbides in a martensitic $9 \% \mathrm{Cr}$ steel after tempering, aging and creep. Philos. Mag. 93, 2259-2268.

Kitahara, H., Ueji, R., Tsuji, N., Minamino, Y., 2006. Crystallographic features of lath martensite in low-carbon steel. Acta Mater. 54, 1279-1288.

Koning, M. De, Miller, R., Bulatov, V.V., Abraham, F.F., 2002. Modelling grainboundary resistance in intergranular dislocation slip transmission. Philos. Mag. A 82, 2511-2527.

Krauss, G., 1999. Martensite in steel: strength and structure. Mater. Sci. Eng. A 273-275, 40-57.

Krom, A.H.M., Koers, R.W.J., Bakker, A., 1999. Hydrogen transport near a blunting crack tip. J. Mech. Phys. Solids 47, 971-992.

Kubin, L., Devincre, B., Hoc, T., 2008a. Modeling dislocation storage rates and mean free paths in face-centered cubic crystals. Acta Mater. 56, 6040-6049.

Kubin, L., Devincre, B., Hoc, T., 2008b. Toward a physical model for strain hardening in fcc crystals. Mater. Sci. Eng. A 483-484, 19-24.

Kubin, L.., Mortensen, A., 2003. Geometrically necessary dislocations and straingradient plasticity: a few critical issues. Scr. Mater. 48, 119-125.

Lee, S., Ronevich, J.A., Krauss, G., Matlock, D.K., 2010. Hydrogen Embrittlement of Hardened Low-carbon Sheet Steel 50, 294-301.

Lee, T.C., Robertson, I.M., Birnbaum, H.K., 1990. An In Situ Transmission Electron Microscope Deformation Study of the Slip Transfer Mechanisms in Metals. Metall. Trans. A 21, 2437-2447. 
Lee, Y., Gangloff, R.P., 2007. Measurement and Modeling of Hydrogen EnvironmentAssisted Cracking of Ultra-High-Strength Steel. Metall. Mater. Trans. A 38, 2174 2190.

Lufrano, J., Sofronis, P., Birnbaum, H.K., 1996. Modeling of hydrogen transport and elastically accommodated hydride formation near a crack tip. J. Mech. Phys. Solids 44, 179-205.

Lynch, S., 2012. Hydrogen embrittlement phenomena and mechanisms a ). Corros. Rev. $30,105-123$.

Ma, A., Roters, F., Raabe, D., 2006. On the consideration of interactions between dislocations and grain boundaries in crystal plasticity finite element modeling Theory, experiments, and simulations. Acta Mater. 54, 2181-2194.

Martin, M.L., Fenske, J. a., Liu, G.S., Sofronis, P., Robertson, I.M., 2011. On the formation and nature of quasi-cleavage fracture surfaces in hydrogen embrittled steels. Acta Mater. 59, 1601-1606.

Miresmaeili, R., Saintier, N., Notsu, H., Olive, J.-M., Kanayama, H., 2010. One-Way Coupled Crystal Plasticity-Hydrogen Diffusion Simulation on Artificial Microstructure. J. Comput. Sci. Technol. 4, 105-120.

Morito, S., Huang, X., Furuhara, T., Maki, T., Hansen, N., 2006. The morphology and crystallography of lath martensite in alloy steels. Acta Mater. 54, 5323-5331.

Morito, S., Tanaka, H., Konishi, R., Furuhara, T., Maki, T., 2003. The morphology and crystallography of lath martensite in Fe-C alloys. Acta Mater. 51, 1789-1799.

Morris, J.W., 2011. On the Ductile-Brittle Transition in Lath Martensitic Steel. ISIJ Int. $51,1569-1575$.

Musienko, A., Cailletaud, G., 2009. Simulation of inter- and transgranular crack propagation in polycrystalline aggregates due to stress corrosion cracking. Acta Mater. 57, 3840-3855.

Nagao, A., Smith, C.D., Dadfarnia, M., Sofronis, P., Robertson, I.M., 2012. The role of hydrogen in hydrogen embrittlement fracture of lath martensitic steel. Acta Mater. $60,5182-5189$.

Olden, V., Thaulow, C., Johnsen, R., 2008a. Modelling of hydrogen diffusion and hydrogen induced cracking in supermartensitic and duplex stainless steels. Mater. Des. 29, 1934-1948. 
Olden, V., Thaulow, C., Johnsen, R., Østby, E., Berstad, T., 2008b. Application of hydrogen influenced cohesive laws in the prediction of hydrogen induced stress cracking in $25 \% \mathrm{Cr}$ duplex stainless steel. Eng. Fract. Mech. 75, 2333-2351.

Oriani, R.A., Josephic, P.H., 1974. Equilibrium aspects of hydrogen-induced cracking of steels. Acta Metall. 22, 1065-1074.

Oriani, R.A., Josephic, P.H., 1977. Equilibrium and kinetic studies of the hydrogenassisted cracking of steel. Acta Metall. 25, 979-988.

Padilha, A.F., Rios, P.R., 2002. Decomposition of Austenite in Austenitic Stainless Steels $42,325-337$.

Pouillier, E., Gourgues, a.-F., Tanguy, D., Busso, E.P., 2012. A study of intergranular fracture in an aluminium alloy due to hydrogen embrittlement. Int. J. Plast. 34, 139153.

Ramamurthy, S., Atrens, A., 2013. Stress corrosion cracking of high-strength steels. Corros. Rev. 31, 1-31.

Randle, V., Davies, P., 2005. Crystallography of brittle fracture and deformation twinning in ferritic steels. Mater. Sci. Technol. 21, 1275-1281.

Rezvanian, O., Zikry, M.A., Rajendran, A.M., 2007. Statistically stored, geometrically necessary and grain boundary dislocation densities: microstructural representation and modelling. Proc. R. Soc. A Math. Phys. Eng. Sci. 463, 2833-2853.

Rimoli, J.J., Ortiz, M., 2010. A three-dimensional multiscale model of intergranular hydrogen-assisted cracking. Philos. Mag. 90, 2939-2963.

Roters, F., Eisenlohr, P., Hantcherli, L., Tjahjanto, D.D., Bieler, T.R., Raabe, D., 2010. Overview of constitutive laws, kinematics, homogenization and multiscale methods in crystal plasticity finite-element modeling: Theory, experiments, applications. Acta Mater. 58, 1152-1211.

Sangid, M.D., Ezaz, T., Sehitoglu, H., Robertson, I.M., 2011. Energy of slip transmission and nucleation at grain boundaries. Acta Mater. 59, 283-296.

Serebrinsky, S., Carter, E.A., Ortiz, M., 2004. A quantum-mechanically informed continuum model of hydrogen embrittlement. J. Mech. Phys. Solids 52, 2403-2430.

Shanthraj, P., Zikry, M.A., 2011. Dislocation density evolution and interactions in crystalline materials. Acta Mater. 59, 7695-7702.

Shanthraj, P., Zikry, M.A., 2012. Dislocation-density mechanisms for void interactions in crystalline materials. Int. J. Plast. 34, 154-163. 
Shanthraj, P., Zikry, M.A., 2013. Microstructurally induced fracture nucleation and propagation in martensitic steels. J. Mech. Phys. Solids 61, 1091-1105.

Shen, Y.Z., Kim, S.H., Cho, H.D., Han, C.H., Ryu, W.S., 2012. Precipitates in normalized and tempered $10 \% \mathrm{Cr}$ ferritic/martensitic steels. J. Nucl. Mater. 430, 264269.

Shi, J., Zikry, M. a., 2009. Grain-boundary interactions and orientation effects on crack behavior in polycrystalline aggregates. Int. J. Solids Struct. 46, 3914-3925.

Shibata, A., Takahashi, H., Tsuji, N., 2012. Microstructural and Crystallographic Features of Hydrogen-related Crack Propagation in Low Carbon Martensitic Steel. ISIJ Int. 52, 208-212.

Shtansky, D. V, Nakai, K., Ohmori, Y., 2000. Crystallography and structural evolution during reverse transformation in an $\mathrm{Fe}-17 \mathrm{Cr}-0.5 \mathrm{C}$ tempered martensite. Acta Mater. 48, 1679-1689.

Sofronis, P., McMeeking, R.M., 1989. Numerical analysis of hydrogen transport near a blunting crack tip. J. Mech. Phys. Solids 37, 317-350.

Song, J., Curtin, W. a, 2013. Atomic mechanism and prediction of hydrogen embrittlement in iron. Nat. Mater. 12, 145-51.

Song, Y.Y., Ping, D.H., Yin, F.X., Li, X.Y., Li, Y.Y., 2010. Microstructural evolution and low temperature impact toughness of a $\mathrm{Fe}-13 \% \mathrm{Cr}-4 \% \mathrm{Ni}-\mathrm{Mo}$ martensitic stainless steel. Mater. Sci. Eng. A 527, 614-618.

Taha, A., Sofronis, P., 2001. A micromechanics approach to the study of hydrogen transport and embrittlement. Eng. Fract. Mech. 68, 803-837.

Taneike, M., Sawada, K., Abe, F., 2004. Effect of Carbon Concentration on Precipitation Behavior of M 23 C 6 Carbides and MX Carbonitrides in Martensitic 9Cr Steel during Heat Treatment 35.

Terada, M., Saiki, M., Costa, I., Padilha, A.F., 2006. Microstructure and intergranular corrosion of the austenitic stainless steel 1.4970. J. Nucl. Mater. 358, 40-46.

Wang, C., Wang, M., Shi, J., Hui, W., Dong, H., 2008. Effect of microstructural refinement on the toughness of low carbon martensitic steel. Scr. Mater. 58, 492495.

Wang, M., Akiyama, E., Tsuzaki, K., 2005. Effect of hydrogen and stress concentration on the notch tensile strength of AISI 4135 steel. Mater. Sci. Eng. A 398, 37-46. 
Wang, M., Akiyama, E., Tsuzaki, K., 2007. Effect of hydrogen on the fracture behavior of high strength steel during slow strain rate test. Corros. Sci. 49, 4081-4097.

Wu, Q., Shanthraj, P., Zikry, M.A., 2013. Modeling the heterogeneous effects of retained austenite on the behavior of martensitic high strength steels. Int. J. Fract. 184, 241252.

Wu, Q., Zikry, M.A., 2014. Microstructural modeling of crack nucleation and propagation in high strength martensitic steels. Int. J. Solids Struct. 51, 4345-4356.

Ziaei, S., Zikry, M.A., 2014. Modeling the Effects of Dislocation - Density Interaction, Generation, and Recovery on the Behavior of H.C.P. Materials. Metall. Mater. Trans. A. in press.

Zikry, M.A., 1994. An accurate and stable algorithm for high strain-rate finite strain plasticity. Comput. Struct. 50, 337-350.

Zikry, M.A., Kao, M., 1996. Inelastic microstructural failure mechanisms in crystalline materials with high angle grain boundaries. J. Mech. Phys. Solids 44, 1765-1798.

\section{List of figures}

Fig. 1 Decomposition of a cracked element with two overlapping elements.

Fig. 2 Microstructural model, carbide precipitates $\mathrm{M}_{23} \mathrm{C}_{6}$, and block/packet arrangement.

Fig. 3 Hydrogen diffusion behavior, (a) hydrogen concentration at 2\% nominal strain, (b) hydrogen concentration at 6\% nominal strain, (c) pressure, (d) norm of pressure gradient.

Fig. 4 Behavior at $6 \%$ nominal strain, (a) immobile dislocation density for the active slip system $(1 \overline{1} 2)[\overline{1} 11]$, (b) GB transmission factor for slip system $(1 \overline{1} 2)[\overline{1} 11]$, (c) normal stress, (d) shear slip.

Fig. 5 Hydrogen assisted cracking behavior, (a) maximum stress on $\{100\}$ planes at $1 \%$ nominal strain, (b) maximum stress on $\{110\}$ planes at $1 \%$ nominal strain, (c) normal stress at $1.8 \%$ nominal strain, (d) normal stress at $2.2 \%$ nominal strain. 
Fig. 6 Hydrogen embrittlement behavior at 2.2\% nominal strain, (a) pressure, (b) norm of pressure gradient, (c) hydrogen concentration, (d) reduction of critical fracture stress on $\{110\}$ planes.

Fig. 7 Stress-strain curves for the hydrogen embrittlement case, and the case without embrittlement.

Fig. 8 Comparison between the hydrogen embrittlement case and the case without embrittlement, total dislocation density generation, (a) for the hydrogen embrittlement case at $2.8 \%$ nominal strain, (b) for the case without embrittlement at $10 \%$ nominal strain; shear slip, (c) for the hydrogen embrittlement case at $2.8 \%$ nominal strain, (d) for the case without embrittlement at $10 \%$ nominal strain.

Fig. 9 Comparison of GND dislocation density loop between the hydrogen embrittlement case and the case without embrittlement, GND screw dislocation density of slip system (110)[11 1$]$ for the hydrogen embrittlement case, (a) at 1.7\% nominal strain, (b) at $2.8 \%$ nominal strain; GND screw dislocation density of slip system (110)[1 $\overline{1} 1]$ for the case without embrittlement, (c) at 6\% nominal strain, (d) at 8.4\% nominal strain.

Fig. 10 Comparison of crack length for the hydrogen embrittlement case and the case without embrittlement.

Fig. 11 Hydrogen embrittlement behavior for the case with a pre-existing crack at $0.3 \%$ nominal strain, (a) pressure, (b) norm of pressure gradient, (c) hydrogen concentration, (d) reduction of critical fracture stress on $\{110\}$ planes. 
Fig. 12 Comparison of normal stress at $2 \%$ nominal strain with a pre-existing crack for, (a) the hydrogen embrittlement case and (b) the case without embrittlement.

Fig. 13 Comparison of crack length for the hydrogen embrittlement case and the case without embrittlement, with a pre-existing crack.

Fig. 14 Comparison between the hydrogen embrittlement case and the case without

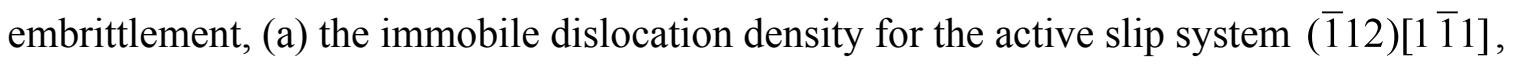
for the hydrogen embrittlement case at $2 \%$ nominal strain, (b) the immobile dislocation density for the active slip system $(11 \overline{2})[111]$, for the case without embrittlement at $4 \%$ nominal strain, (c) shear slip, for the hydrogen embrittlement case at $2 \%$ nominal strain, (d) shear slip, for the case without embrittlement at 4\% nominal strain. 

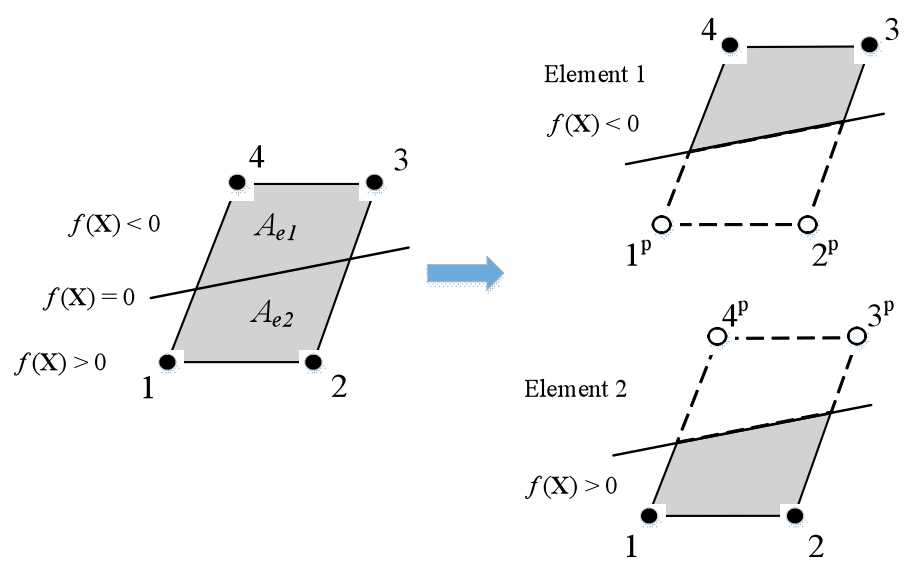

Fig. 1 Decomposition of a cracked element with two overlapping elements.

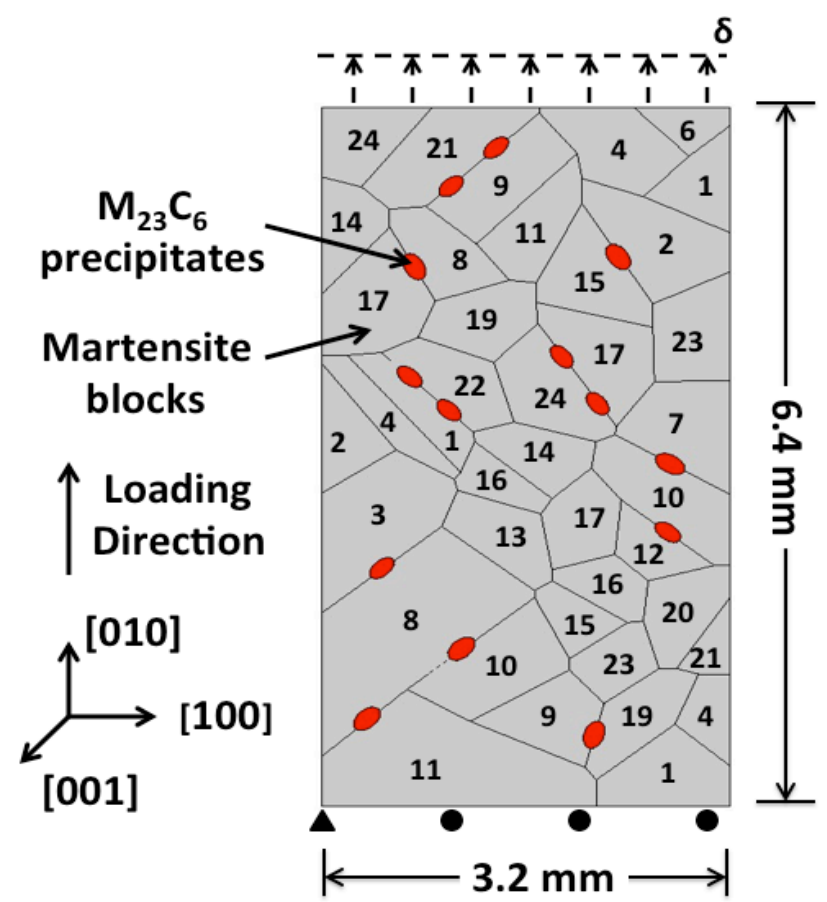

Fig. 2 Microstructural model, carbide precipitates $\mathrm{M}_{23} \mathrm{C}_{6}$, and block/packet arrangement. 


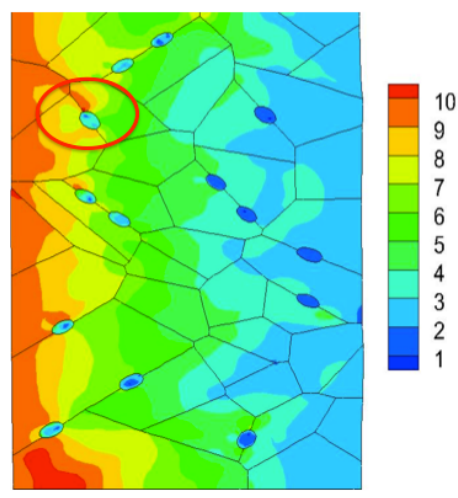

(a)

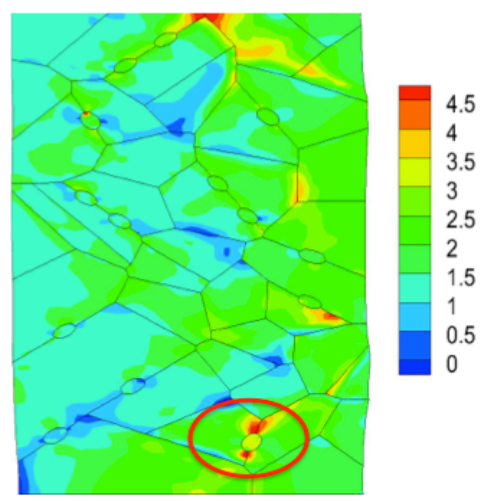

(c)

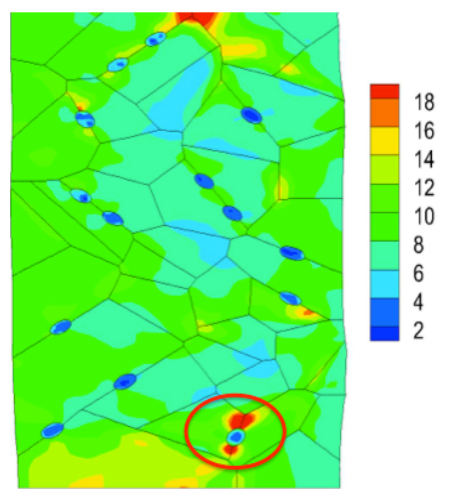

(b)

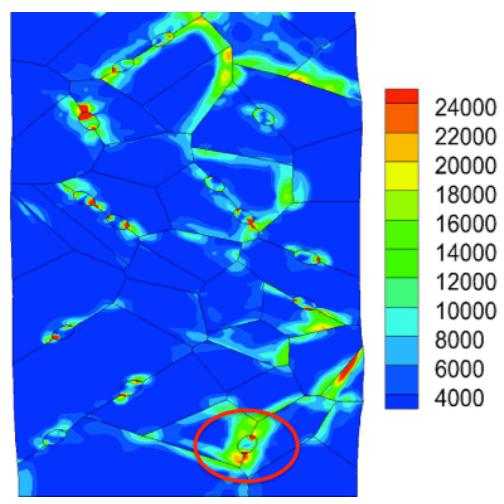

(d)

Fig. 3 Hydrogen diffusion behavior, (a) hydrogen concentration at 2\% nominal strain, (b) hydrogen concentration at $6 \%$ nominal strain, (c) pressure, (d) norm of pressure gradient.

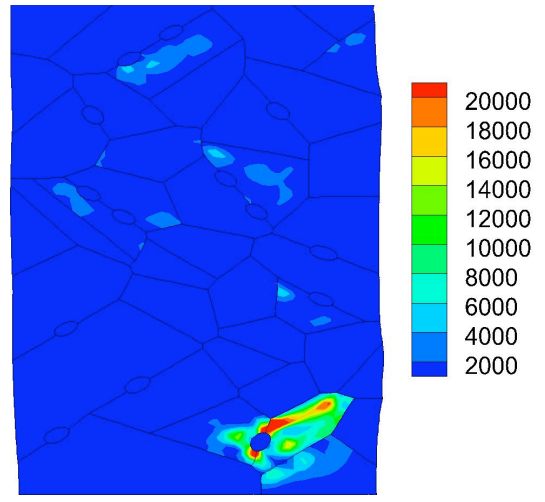

(a)

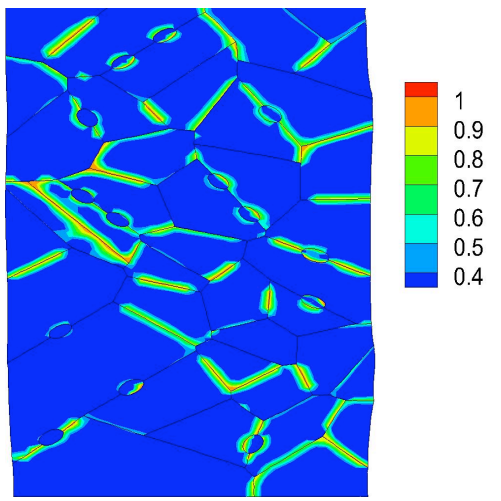

(b) 


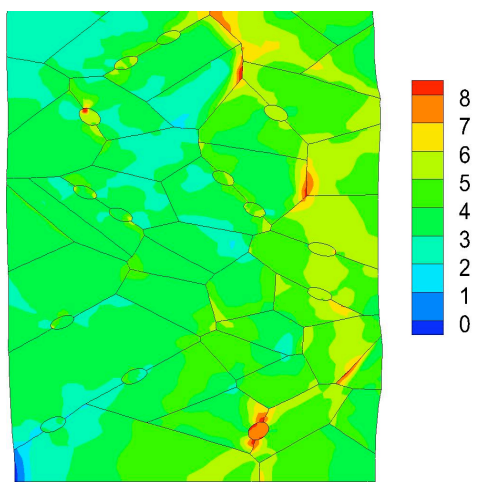

(c)

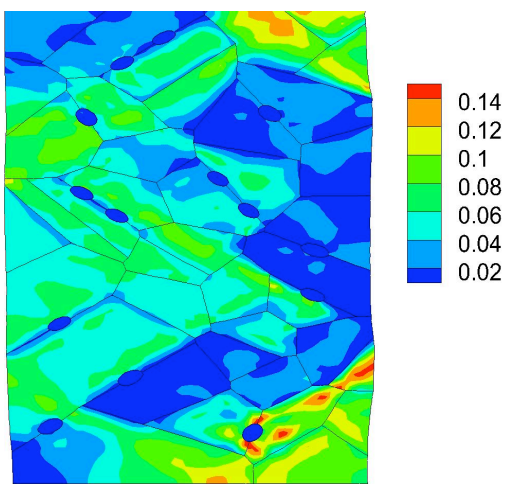

(d)

Fig. 4 Behavior at $6 \%$ nominal strain, (a) immobile dislocation density for the active slip system (1 $\overline{1} 2)[\overline{1} 11]$, (b) GB transmission factor for slip system (1 $\overline{1} 2)[\overline{1} 11]$, (c) normal stress, (d) shear slip.

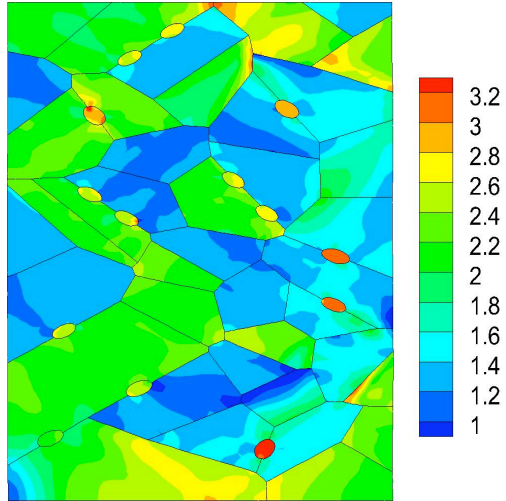

(a)

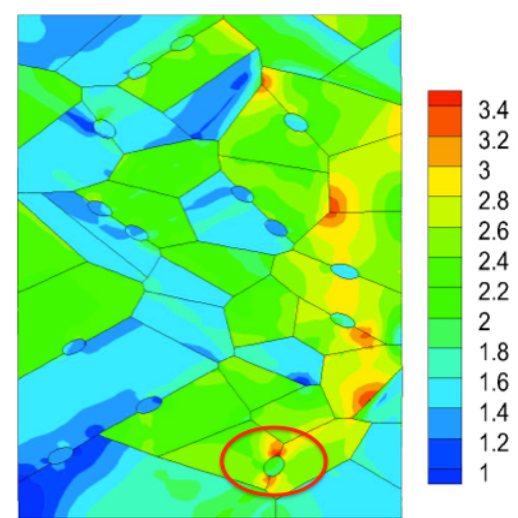

(b) 


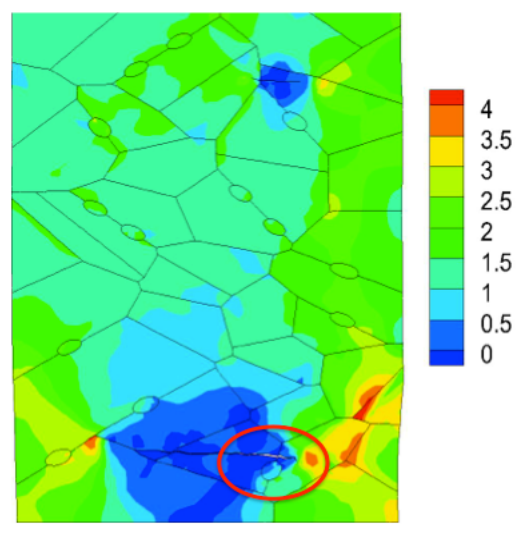

(c)

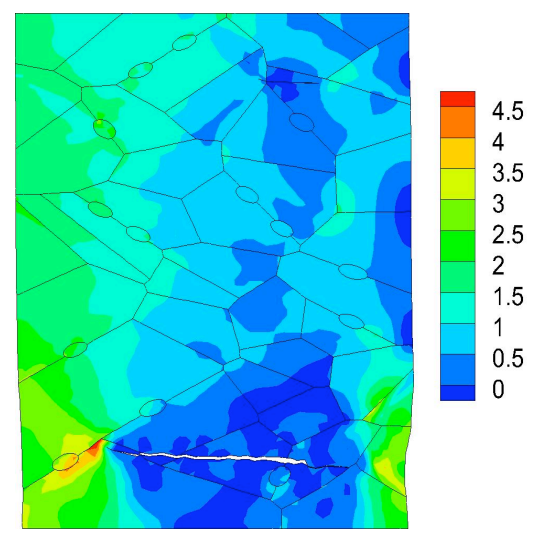

(d)

Fig. 5 Diffusion assisted hydrogen cracking behavior, (a) maximum stress on $\{100\}$ planes at $1 \%$ nominal strain, (b) maximum stress on $\{110\}$ planes at $1 \%$ nominal strain, (c) normal stress at $1.8 \%$ nominal strain, (d) normal stress at $2.2 \%$ nominal strain.

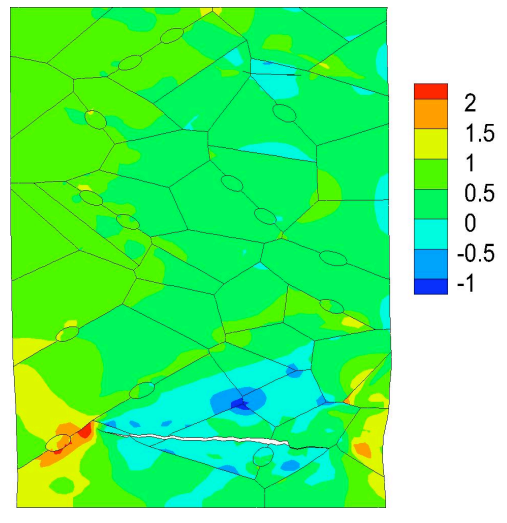

(a)

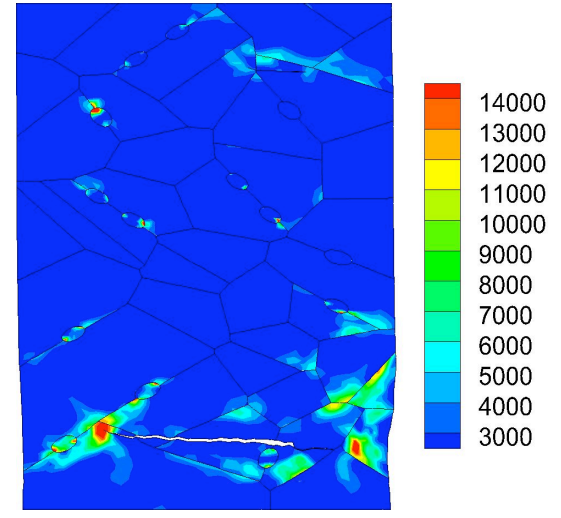

(b) 


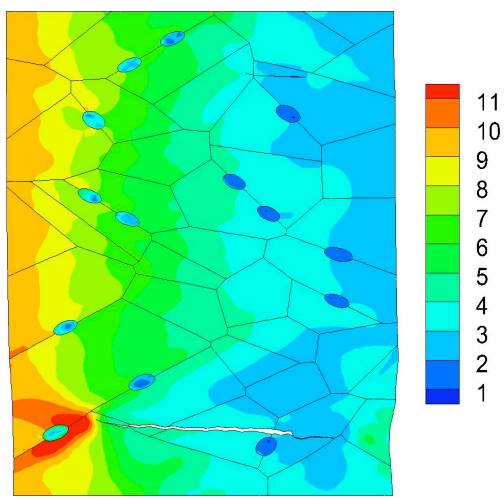

(c)

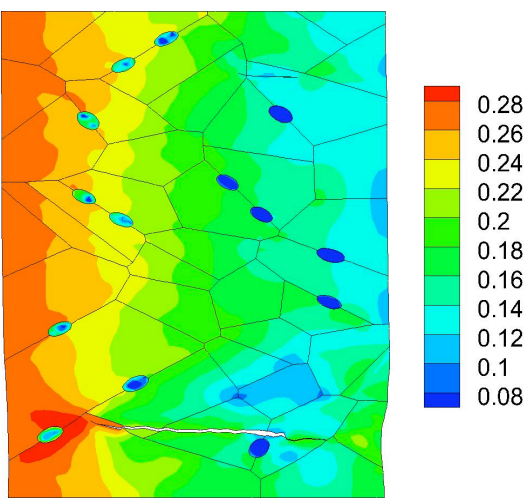

(d)

Fig. 6 Hydrogen embrittlement behavior at 2.2\% nominal strain, (a) pressure, (b) norm of pressure gradient, (c) hydrogen concentration, (d) reduction of critical fracture stress on $\{110\}$ planes.

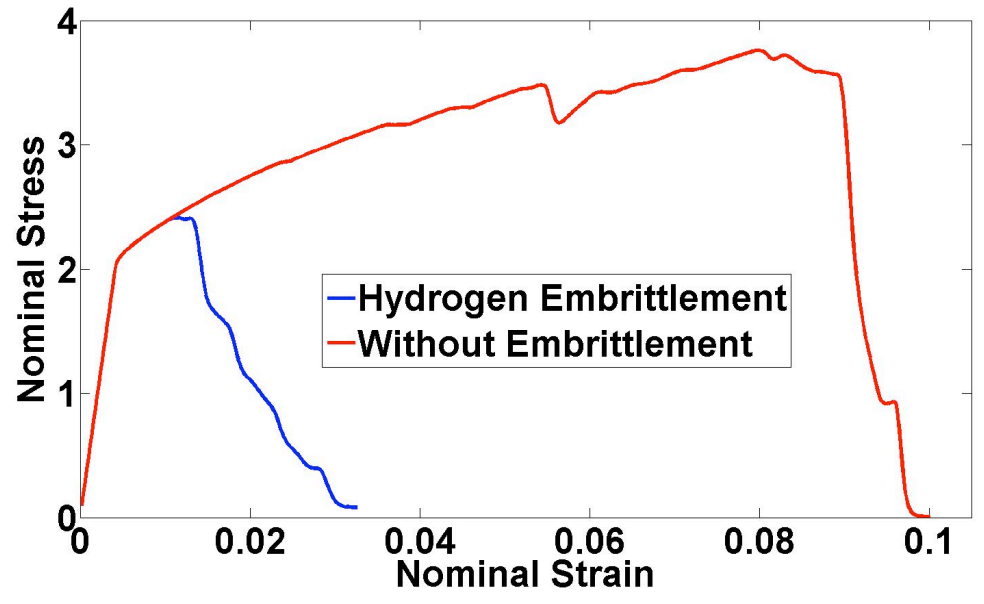

Fig. 7 Stress-strain curves for the hydrogen embrittlement case, and the case without embrittlement. 


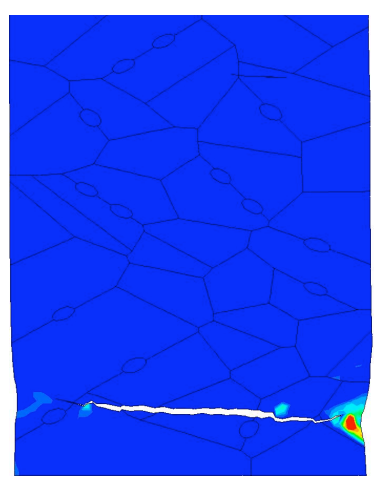

(a)

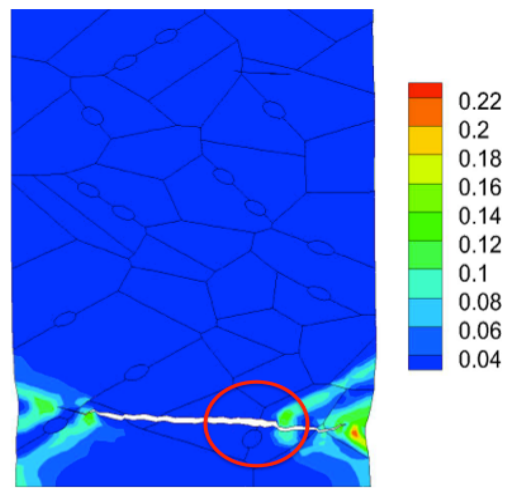

(c)

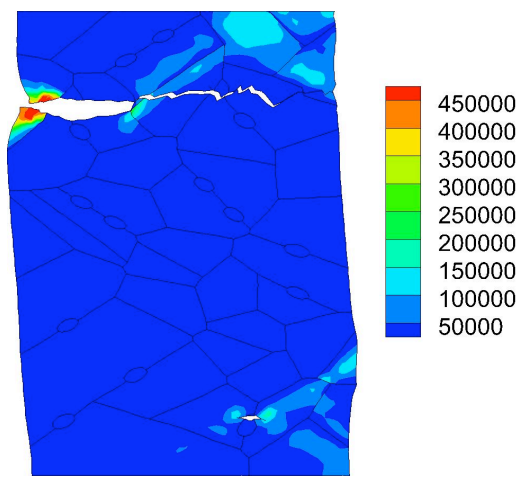

(b)

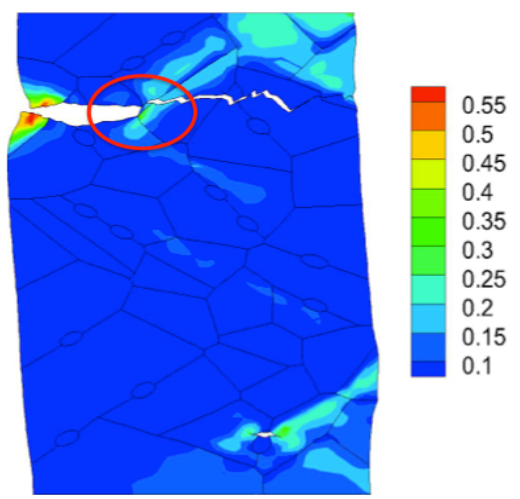

(d)

Fig. 8 Comparison between the hydrogen embrittlement case and the case without embrittlement, total dislocation density generation, (a) for the hydrogen embrittlement case at $2.8 \%$ nominal strain, (b) for the case without embrittlement at $10 \%$ nominal strain; shear slip, (c) for the hydrogen embrittlement case at 2.8\% nominal strain, (d) for the case without embrittlement at 10\% nominal strain. 

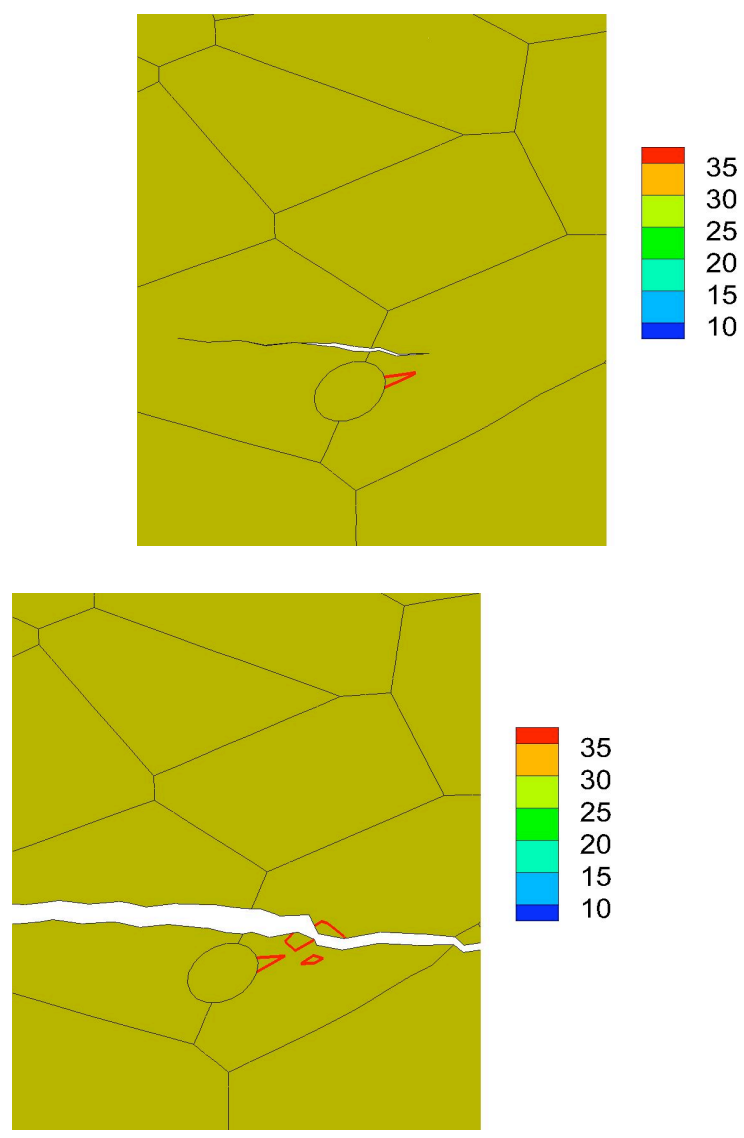

(a)

(b)

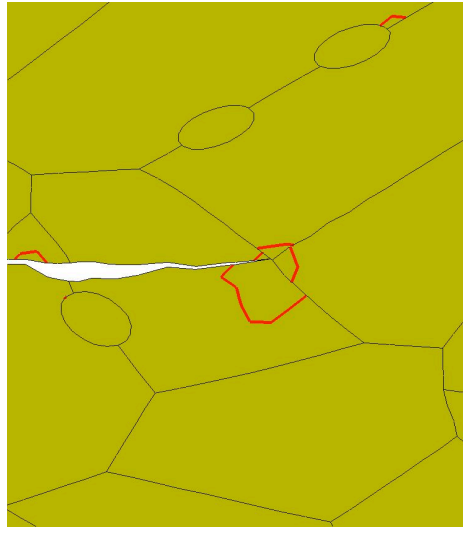

(c)

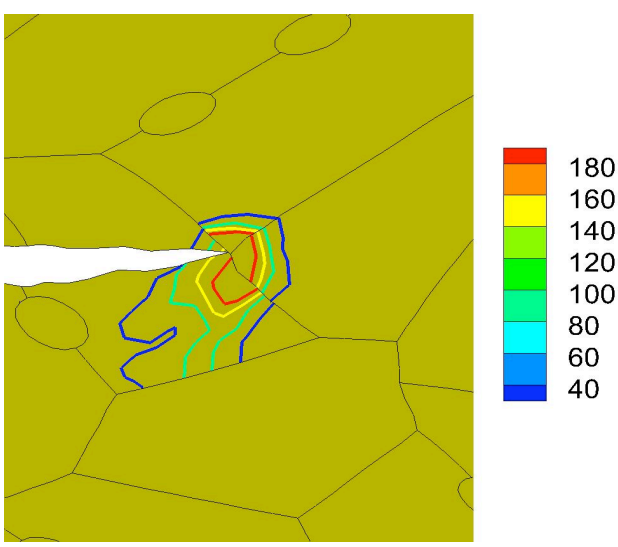

(d)

Fig. 9 Comparison of GND dislocation density loop between the hydrogen embrittlement case and the case without embrittlement, GND screw dislocation density of slip system 
$(\overline{1} 10)[11 \overline{1}]$ for the hydrogen embrittlement case, (a) at 1.7\% nominal strain, (b) at $2.8 \%$ nominal strain; GND screw dislocation density of slip system (110)[1 $\overline{1} 1]$ for the case without embrittlement, (c) at 6\% nominal strain, (d) at 8.4\% nominal strain.

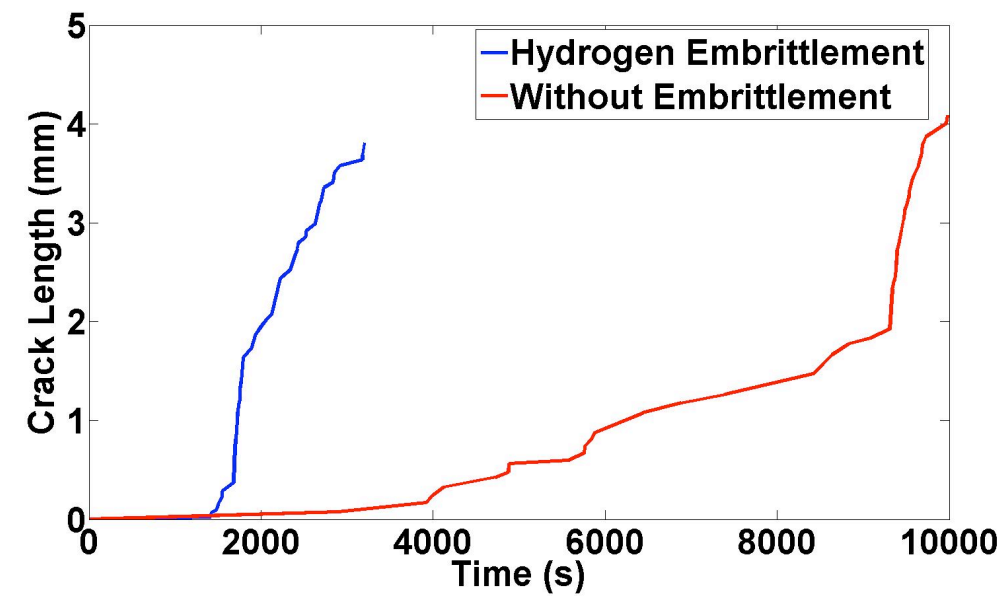

Fig. 10 Comparison of crack length for the hydrogen embrittlement case and the case without embrittlement.

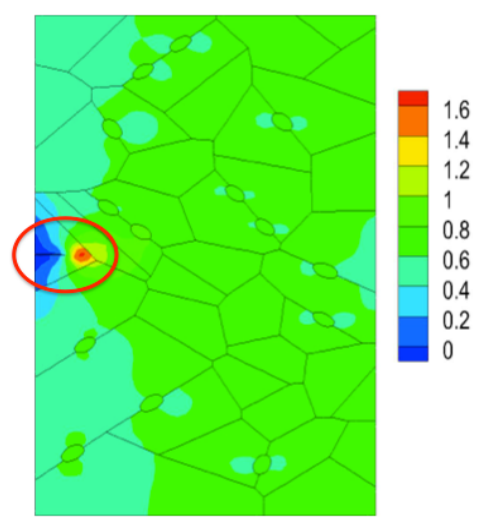

(a)

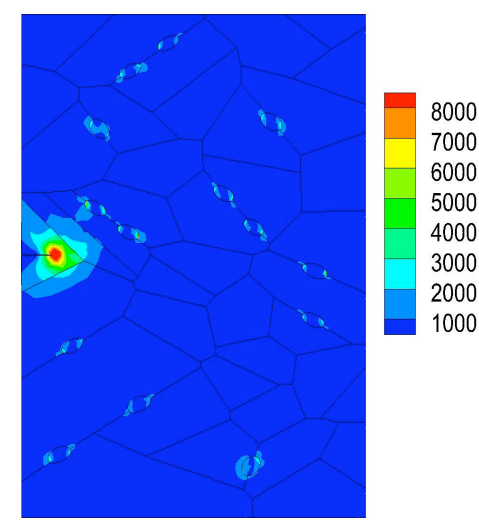

(b) 


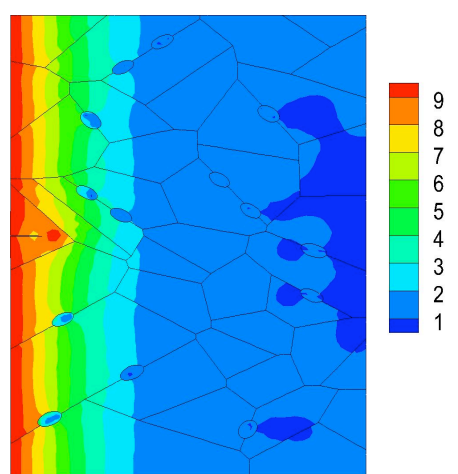

(c)

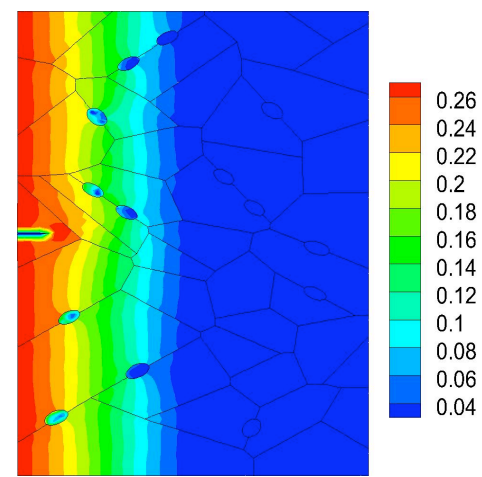

(d)

Fig. 11 Hydrogen embrittlement behavior for the case with a pre-existing crack at $0.3 \%$ nominal strain, (a) pressure, (b) norm of pressure gradient, (c) hydrogen concentration, (d) reduction of critical fracture stress on $\{110\}$ planes.

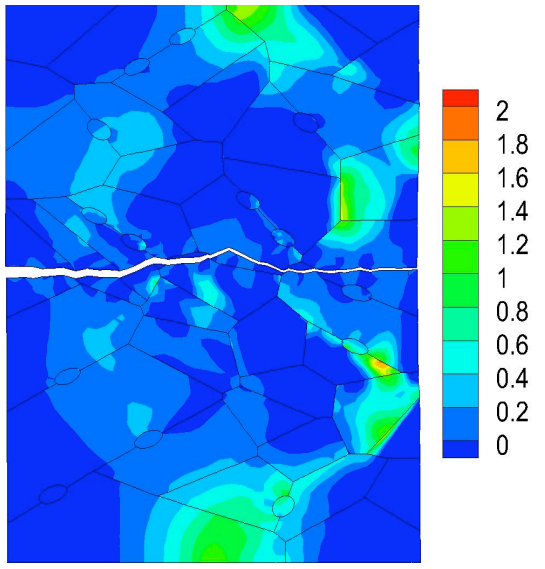

(a)

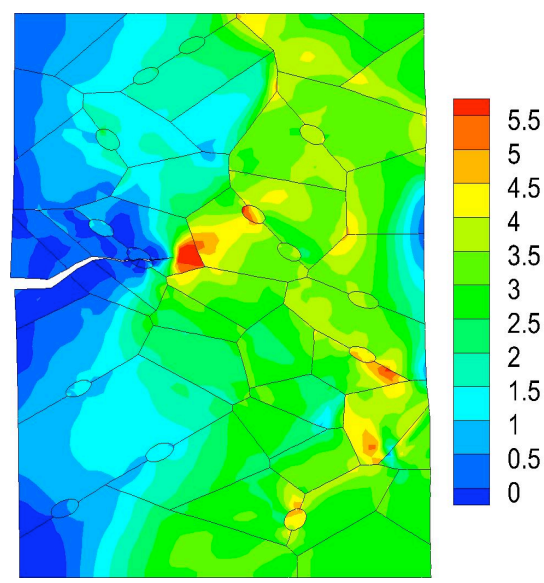

(b)

Fig. 12 Comparison of normal stress at 2\% nominal strain with a pre-existing crack for,

(a) the hydrogen embrittlement case and (b) the case without embrittlement. 


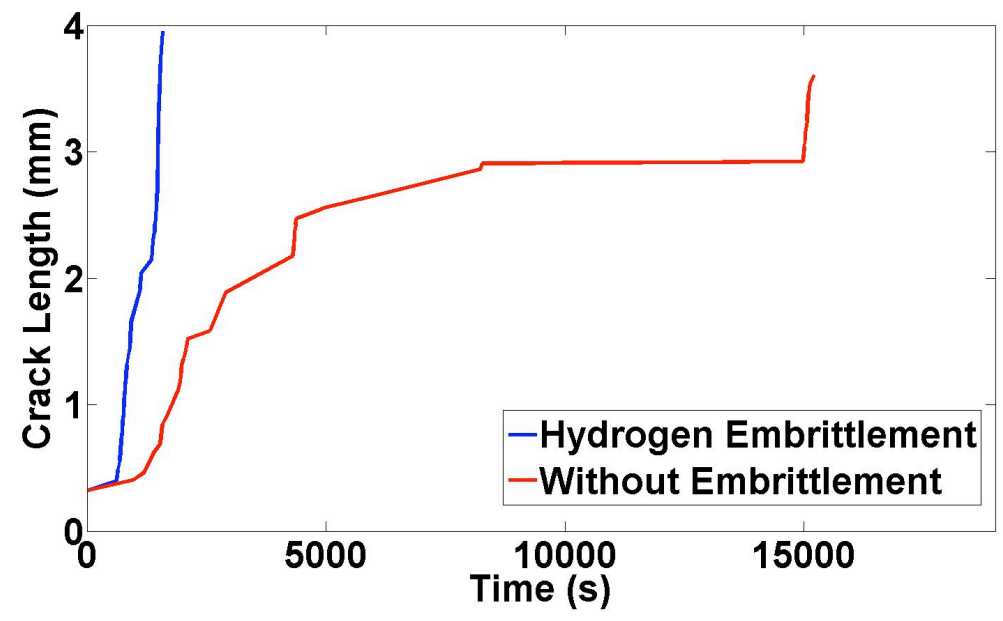

Fig. 13 Comparison of crack length for the hydrogen embrittlement case and the case without embrittlement, with a pre-existing crack.

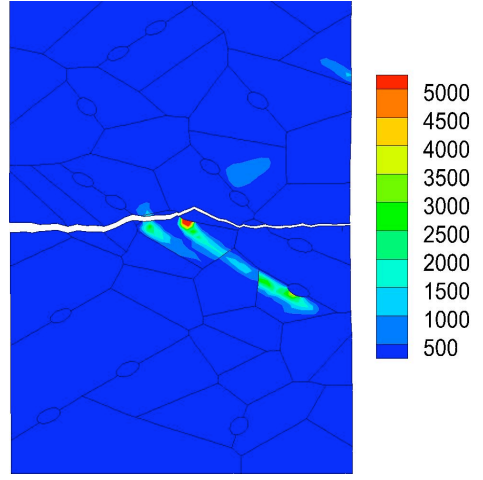

(a)

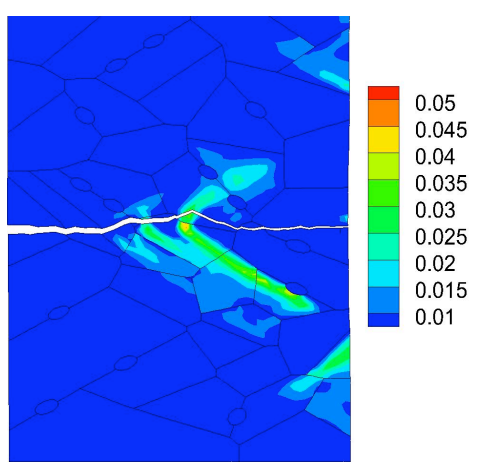

(c)

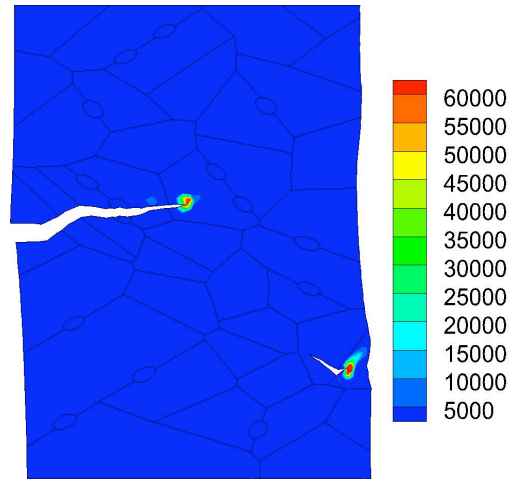

(b)

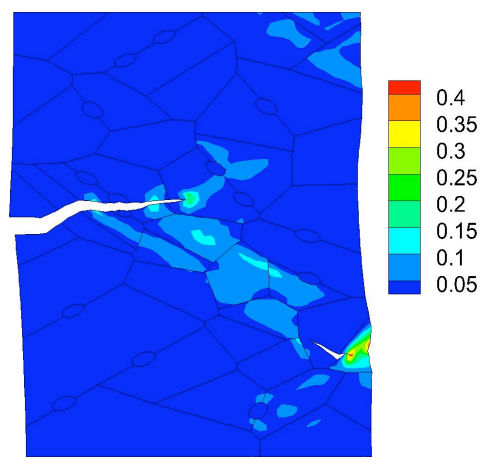

(d) 
Fig. 14 Comparison between the hydrogen embrittlement case and the case without embrittlement, (a) the immobile dislocation density for the active slip system ( $\overline{1} 12)[1 \overline{1} 1]$, for the hydrogen embrittlement case at $2 \%$ nominal strain, (b) the immobile dislocation density for the active slip system $(11 \overline{2})[111]$, for the case without embrittlement at $4 \%$ nominal strain, (c) shear slip, for the hydrogen embrittlement case at $2 \%$ nominal strain, (d) shear slip, for the case without embrittlement at 4\% nominal strain. 